\title{
Tailoring the microstructural, magnetic and dielectric properties of vanadium ions substituted nickel ferrite nanocrystals
}

Kamar Tanbir

ACNN, AKU, Patna, Bihar

MRITUNJOY PRASAD GHOSH

National Institute of Technology Patna

Manoranjan Kar

IIT Patna: Indian Institute of Technology Patna

Samrat Mukherjee ( $\nabla$ samrat.udc@gmail.com )

National Institute of Technology Patna https://orcid.org/0000-0002-5653-1244

\section{Research Article}

Keywords: ferrite nanocrystals, Williamson-Hall plots, optical absorption, magnetic properties, Cole- Cole plots

Posted Date: February 23rd, 2021

DOl: https://doi.org/10.21203/rs.3.rs-164719/v1

License: (c) (i) This work is licensed under a Creative Commons Attribution 4.0 International License. Read Full License

Version of Record: A version of this preprint was published at Journal of Materials Science: Materials in Electronics on March 18th, 2021. See the published version at https://doi.org/10.1007/s10854-02105671-6. 


\title{
Tailoring the microstructural, magnetic and dielectric properties of vanadium ions substituted nickel ferrite nanocrystals
}

\author{
Kamar Tanbir ${ }^{1}$, Mritunjoy Prasad Ghosh ${ }^{2}$, Manoranjan $\mathrm{Kar}^{3}$, Samrat Mukherjee ${ }^{2, *}$

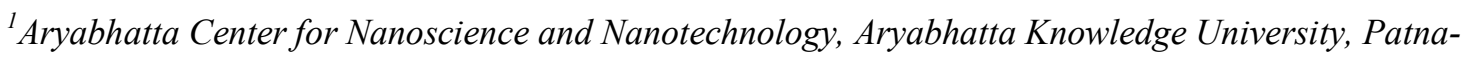 \\ 800001, Bihar, India. \\ ${ }^{2}$ Department of Physics, National Institute of Technology Patna, Patna-800005, Bihar, India \\ ${ }^{3}$ Department of Physics, Indian Institute of Technology Patna, Patna-800013, Bihar, India \\ *Corresponding author's email id: samrat.udc@gmail.com
}

\begin{abstract}
This paper describes the composition-dependent microstructural, magnetic and dielectric properties of vanadium ions doped nickel ferrite nanoparticles. All the nanoferrite samples $\left(\mathrm{NiV}_{\mathrm{x}} \mathrm{Fe}_{2-\mathrm{x}} \mathrm{O}_{4}: \mathrm{x}=0.00\right.$, $0.05,0.10$ and 0.15 ) were prepared using conventional co-precipitation method. X-ray diffraction patterns verified the single cubic spinel phase formation and achievement of nano-sized ferrite particles with a homogeneous distribution, which was also supported by HRTEM micrographs. Mean crystallite diameter was seen in the range of $05 \mathrm{~nm}$ to $12 \mathrm{~nm}$ as evaluated from Williamson-Hall (WH) curves for the different doped samples. A compressive nature microstrain was noticed in all the samples and was also seen to reduce with the enhancement of vanadium ions content. A blue shift was detected in the indirect band gap for higher vanadium doped samples. Magnetization at the saturation point as well as coercive field both were observed to reduce at room temperature with increasing vanadium concentration in nanosized nickel ferrites. Room temperature dielectric characteristics of all the synthesized samples ensured that the elementary charge conduction process was governed by the hopping of electrons. Cole-Cole plots also showed that the grain boundaries play an important task in deciding the dielectric responses.
\end{abstract}

Keywords: ferrite nanocrystals; Williamson-Hall plots; optical absorption; magnetic properties; ColeCole plots

\section{Introduction}

Although several magnetic materials (lodestone and ferrites) were invented in ancient era and magnetite was used first to make compass for navigation purposes but ferrites are still the active area of research from fundamental as well as technological points of view. It is due to their excellent stability, ferrimagnetic behavior, high Néel temperature, excellent coercive field and dielectric nature. Even small modifications in magnetic properties of ferrites such as coercive field, saturation 
magnetization, Néel temperature and permeability can have significant impact on present day technology as well as economy [1-4]. Ferrites are the special class of magnetic material widely used for various microwave applications as ferrimagnetic iron oxides are extremely functional because of they exhibit properties of a magnetic material along with an electrical insulator. According to the primary crystal structure, ferrites are commonly classified into three broad categories i.e. spinel ferrites, hexagonal ferrites and garnets. Among all these ferrites, cubic spinel ferrites are the first choice of researchers because of their tunable physical properties and flexibilities in technological applications $[5,6]$.

In last three decades, various types of nanostructured ferrite systems have become a topic of massive interest for researchers. Most important use of various ferrite nanostructures is related to the magnetic recording technology and biomedical applications. The gradual increment in areal bit density of magnetic disks has been performed with the help of nanoscale magnetism. Following the fast evaluation of component density of electronic circuits, the density of magnetic storage in hard disks has progressed much faster in recent years. To attain greater storage density, the properties of magnetic nanoparticles are needed to be examined thoroughly [6-9]. The proper understanding of magnetic phenomenon can be directly implanted in to the technological applications [1-3]. The generation of completely new phenomena for nanoscopic magnetic systems with respect to bulk materials has its origin in critical dimension of domains, breaking translation symmetry, reduced surface co-ordination number, broken exchange bonds, spins disorder, spins pinning and frustration [2]. Other impotent factors that modify the magnetic properties of nanomaterials are dipole-dipole interactions, use of capping layer and texture of nano-objects. Also the existence of imperfections, defects and preparation method plays a crucial role in determining the magnetic properties of nanomaterials [9-11].

The magnetic nanoparticles can be synthesized using several top down and bottom up procedures. Among the entire bottom up chemical synthesis route, the standard soft chemical co-precipitation method provides better size and shape homogeneity of nanoparticles. Single phase ferrite nanoparticles of few nanometers in diameter can be synthesized using this method and it is also easier, cost effective and time consuming synthesis technique $[10,12,13]$. All the ferrite nanoparticles for the present work have been synthesized using chemical co-precipitation route.

In this work, we have chosen inverse spinel soft nanocrystalline nickel ferrite as host compound. Soft nickel ferrite manifests an almost perfect inverse spinel cubic structure with an inversion factor $\mathrm{i}=$ 0.99. Bulk $\mathrm{NiFe}_{2} \mathrm{O}_{4}$ also reveals excellent saturation magnetization, moderate coercivity, Néel temperature, superior chemical and thermal stability $[12,14]$. Existence of canted surface spins in nickel ferrite nanoparticles was also reported. Paramagnetic vanadium $\left(\mathrm{V}^{3+}\right)$ ions have been selected as the dopant. Few articles on vanadium doped spinel ferrite nanoparticles were reported till now [15, 
16]. Most of the researchers were unable to prepare impurities free spinel ferrite samples [17]. This article aims to understand the change in various physical characteristics due to the percentage variation of vanadium ions in the host system along with proper tuning of all the physical properties.

\section{Experimental details}

\subsection{Preparation of ferrite nanoparticles}

Vanadium ions substituted nickel ferrite nanoparticles with a generic formula $\mathrm{NiV}_{\mathrm{x}} \mathrm{Fe}_{2-\mathrm{x}} \mathrm{O}_{4}(\mathrm{x}=0.00$, $0.05,0.10$ and 0.15 ) were prepared at $300 \mathrm{~K}$ using soft chemical co-precipitation method [10, 12]. All the purchased raw materials were used for synthesizing ferrite nanoparticles without any additional purification. The following chemicals $\mathrm{Ni}\left(\mathrm{NO}_{3}\right)_{2} \cdot 6 \mathrm{H}_{2} \mathrm{O}, \mathrm{Fe}\left(\mathrm{NO}_{3}\right)_{3} \cdot 9 \mathrm{H}_{2} \mathrm{O}$ and $\mathrm{VCl}_{3}$ were used for preparing ferrite nanoparticles. All the chemicals in suitable ratio were incorporated in $200 \mathrm{ml}$ deionized water. Further, the whole solution was stirred continuously using a magnetic stirrer at $600 \mathrm{rpm}$ for 15 minutes to make a homogeneous mixture. Precipitating agent ( $\mathrm{NaOH}$ solution) was then introduced slowly in droplets under identical stirring condition. $\mathrm{NaOH}$ in solution form was mixed in to the mixture until $\mathrm{pH}$ of the mixture reached 11 to ensure no raw elements remain unreacted. The mixture was then digested at $80{ }^{\circ} \mathrm{C}$ for 120 minutes to complete all the chemical reactions. The obtained precipitate was then washed multiple times with de-ionized water and ethanol to get a final $\mathrm{pH}$ of 7. After that, the precipitate was left to dry in open atmosphere [13]. The dried precipitate was then ground into ultrafine powder and also sintered at $500{ }^{\circ} \mathrm{C}$ for $4 \mathrm{hrs}$. Further the synthesized samples were designated as V-00, V-05, V-10 and V-15 in accordance with the increasing vanadium content in nanosized nickel ferrites. All these synthesized nanoferrite samples were utilized for various characterizations.

\subsection{Characterization techniques}

All the synthesized spinel nanoferrite samples were characterized at room temperature using X-ray diffractometer, high resolution transmission electron microscopy (HRTEM), Uv-visible spectrometer, impedance analyzer and VSM measurements. Room temperature powder X-ray diffraction profiles of all samples were obtained with the help of Rigaku: Ultima IV X-ray diffractometer with $\mathrm{Cu}-\mathrm{K}_{\alpha}$ source $(\lambda=1.5406 \AA)$. X-ray diffraction data of all samples were registered at a fixed scan rate of $0.02 \% \mathrm{sec}$ in the range of $20^{\circ} \leq 2 \theta \leq 80^{\circ}$. Morphology of the ferrite nanoparticles was examined using HRTEM (HRTEM; JEOL, Japan) images. Magnetic responses were obtained using the vibrating sample magnetometer (Quantum Design, VSM) at $300 \mathrm{~K}$. For recording the optical absorption properties of all synthesized samples, UV DRS spectrometer (UV-2550, Shimadzu, Japan) was used. Room 
temperature dielectric characteristics of all the nanoferrite samples were collected by impedance analyzer (HIOKI 3532-50) in the frequency domain $100 \mathrm{~Hz}$ to $10^{7} \mathrm{~Hz}$.

\section{Results and Discussion}

\subsection{X-ray diffraction studies}

Room temperature x-ray diffractograms of all vanadium doped nanocrystalline cubic spinel nickel ferrites are depicted in figure 1. Observed peaks in diffraction pattern were exhibited an exact match with the JCPDS Card No. 10-325. Rietveld refinement of all obtained diffraction patterns was executed using the GSAS software. A pseudo-voigt function was utilized to shape all the peaks in diffraction profile $[12,13]$. All the diffracted peaks in the profile were marked with their Miller indices. Non-existence of any extra peak other than the cubic spinel ferrite peaks in diffraction profile also ensured the generation of single-phase ferrite nanoparticles. Estimated values of refinement factors $\left(R_{w p}\right.$ and $\left.R_{p}\right)$ were noticed below $3 \%$ together with goodness of fit $\left(\chi_{2}\right)$ within the range of 1.04 to 1.18 which verified the excellent agreement between obtained data and standard diffraction profile. Obtained values of lattice parameters along with refinement factors of all synthesized nanoferrites are displayed in table 1. The most intense (311) peak in diffraction profile was found to be broadened with increasing vanadium ions in nanosized nickel ferrites. The observed broadening in diffractograms is attributed to the basic three reasons, i.e. crystallite size effect, microstrain produced inside the nanocrystals and instrumental broadening effects [18]. The instrumentation broadening effect in total line-width of diffraction peaks was removed by considering the diffraction profile of $\mathrm{LaB}_{6}$ (bulk sample) as a reference. Total FWHM ( $\beta$ ) of diffraction peaks after removing the instrument broadening effects was the simple sum of the broadening due to the crystallite diameter effect and existed microstrain contribution. The overall FWHM $(\beta)$ is then written as [19]

$$
\beta=\left(\beta_{\text {size }}+\beta_{\text {strain }}\right)=\frac{K \lambda}{D \cos \theta}+4 \varepsilon \tan \theta
$$

where ' $\mathrm{K}$ ' is termed as sphericity factor ( 0.9 for the particles having spherical shape), ' $\lambda$ ' is the characteristic wavelength of $\mathrm{Cu} \mathrm{k}_{\alpha} \mathrm{x}$-ray, ' $\varepsilon$ ' shows the microstrain in the nanocrystals, ' $\mathrm{D}$ ' signifies the average crystallite diameter and ' $\theta$ ' is the corresponding Bragg's angle. After proper rearrangement, the equation (1) takes the straight-line equation format as given below [19]

$$
\beta \cos \theta=\varepsilon(4 \sin \theta)+\frac{\mathrm{K} \lambda}{\mathrm{D}}
$$

The straight-line curve while drawing $\beta \cos \theta$ vs $4 \sin \theta$ is termed as Williamson-Hall (W-H) plot. The $\mathrm{W}-\mathrm{H}$ curve of all the vanadium doped nickel nanoferrites is presented in figure 2. Slope of the straight line in Williamson-Hall plot gives the information of microstrain present within the nanocrystals whereas the mean crystallite size is estimated from the intercept on the $\beta \cos \theta$ axis $[18,19]$. Calculated values of mean crystallite sizes were obtained within the range of $05 \mathrm{~nm}$ to $12 \mathrm{~nm}$. With the increment 
of vanadium ions in nickel ferrite nanocrystals, the mean crystallite sizes were found to reduce as displayed in table 1. Presence of compressive microstrain was detected in all samples from W-H plots. For higher vanadium ions content nanoferrite samples, the compressive microstrain was found to reduce. A gradual reduction in lattice constant (a) was noticed for higher vanadium ions content samples. Minute mismatch in ionic radii between $\mathrm{V}^{3+}(0.64 \AA)$ and $\mathrm{Fe}^{3+}(0.645 \AA)$ ions was usually behind for the decrement in lattice constant with increasing vanadium ions in nickel ferrite nanoparticles. Z. K. Heiba et al. also reported the reduction of lattice parameter in vanadium doped $\mathrm{CoFe}_{2} \mathrm{O}_{4}$ nanoparticles [16]. The strength of magnetic interactions for cubic spinel ferrites is usually governed by the distance between magnetic ions along with bond angle between them. Hoping length basically provides the separation between magnetic ions. Hoping lengths for tetrahedral (A) and octahedral (B) sites are obtained using these two formulas [18]

$$
\mathrm{S}_{\mathrm{A}}=\sqrt{3} \frac{\mathrm{a}}{4} \text { and } \mathrm{S}_{\mathrm{B}}=\sqrt{2} \frac{\mathrm{a}}{4}
$$

where ' $a$ ' represents the lattice constant. The estimated values of hoping length for tetrahedral (A) and octahedral (B) sites are displayed in table 2. With the increase of vanadium ions in nickel ferrite nanocrystals, the hopping lengths of both sublattice sites were observed to reduce as the lattice constant decreased gradually. Reduction in hopping length also reflects that less amount of energy is required for charge carriers to overcome the electrostatic energy barrier while moving from one site to another $[12,13]$.

\subsection{HRTEM image studies}

Figure 3(a) and figure 3(b) represent the HRTEM images of V-00 and V-15 ferrite nanopowders respectively. Both the samples displayed nearly spherical shaped nanoparticle along with almost perfect homogeneity in sizes. An attentive investigation of HRTEM micrographs disclosed that the ferrite nanoparticles were slightly agglomerated. This is attributed to the existence of notable interparticle interactions among the magnetic nanoparticles $[10,12]$. Average particle size estimated for V-00 (figure 3(a)) sample was $13 \pm 1 \mathrm{~nm}$ which is found in close agreement with crystallite size as calculated from the W-H plot. The crystallographic (311) lattice plane of V-00 nanoferrite sample is displayed in figure 3(c). The clearly visible parallel (311) lattice planes with an interplanar spacing of $0.251 \mathrm{~nm}$ indicated the high crystalline nature of nickel ferrite nanocrystals. The selected area electron diffraction (SAED) pattern of V-00 sample is depicted in figure 3(d). Observation of several concentric rings in the SAED pattern also verified the high crystallinity of ferrite nanoparticles [13]. Each ring in the SAED pattern represents a specific set of parallel lattice planes. All the clearly observed rings were indexed with their respective Miller indices. An attentive inspection of the SAED pattern revealed that two rings were placed very closely whereas the third one little far from them. 
This type of configuration confirmed that the unit cell of spinel ferrite must contain FCC like crystal structure although the actual structure is complicated [10].

\subsection{Magnetic studies}

Room temperature $\mathrm{M}(\mathrm{H})$ responses of all the samples were registered in presence of $\pm 30 \mathrm{kOe}$ magnetic field which is depicted in figure 4. Obtained values of saturation magnetization $\left(\mathrm{M}_{\mathrm{S}}\right)$ together with coercivity $\left(\mathrm{H}_{\mathrm{C}}\right)$ of all the samples from hysteresis loops are collected in table 3 . A careful observation revealed that the pristine spinel cubic nickel ferrite nanoparticles showed the largest value of both coercive field $\left(\mathrm{H}_{\mathrm{C}}\right)$ and saturation magnetization $\left(\mathrm{M}_{\mathrm{S}}\right)$ at $300 \mathrm{~K}$ with respect to other vanadium doped nanoferrites. Both the coercivity and saturation magnetization were noticed to reduce with increasing vanadium ions percentage in the samples. Emergence of ferrimagnetic ground state in spinel ferrite is ascribed to the indirect quantum-mechanical superexchange (A-O-B) magnetic interactions between magnetic ions of tetrahedral (A) and octahedral (B) sublattices via oxygen anions $[12,18]$. It is well known that vanadium ions show paramagnetic behavior at room temperature $[5,6]$. Incorporation of vanadium ions in nanosized nickel ferrites leads to weakening of superexchange interactions therefore a gradual decrement in coercive field is observed. It is noticed that the average crystallite size was decreased for higher vanadium content samples. Reduction in average crystallite size with the increase of vanadium ions percentage also results in decrement of coercive field. Following the Neel's sublattice model, gross magnetic moment $\left(\mu_{\mathrm{T}}\right)$ for any spinel ferrite is the difference of magnetic moment of octahedral $\left(M_{B}\right)$ and tetrahedral $\left(M_{A}\right)$ co-ordinated sites which is given below [18]

$$
\mu_{T}=M_{B}-M_{A}
$$

Substitution of paramagnetic vanadium ions in nanosized nickel ferrites was responsible for the observed decrement in both coercive field and saturation magnetization at $300 \mathrm{~K}$. The superexchange magnetic (A-O-B) interactions are weakened due to introduction of vanadium ions. The net magnetic moment $\left(\mu_{\mathrm{T}}\right)$ per formula unit (in $\mu_{\mathrm{B}}$ ) can be obtained using the stated relation $[20,21]$

$$
\mu_{\mathrm{T}}=\frac{\mathrm{M}_{\mathrm{S}} \mathrm{M}}{5585}
$$

where ' $\mathrm{M}$ ' signifies the molecular weight and ' $\mathrm{M}_{\mathrm{S}}$ ' shows the saturation magnetization. Overall magnetic moment obtained at $300 \mathrm{~K}$ was noticed to decrease for the higher vanadium ions content as displayed in table 3. Saturation magnetization $\left(\mathrm{M}_{\mathrm{S}}\right)$ of any spinel ferrite system is linearly dependent on the net magnetic moment. Due to the notable reduction in net magnetic moment at $300 \mathrm{~K}$, the saturation magnetization of entire nanoferrites was also observed to reduce significantly [21]. Z. K. Heiba et. al. also observed similar trend in vanadium doped $\mathrm{NiFe}_{2} \mathrm{O}_{4}$ nanoparticles upto a certain limit 
[15]. The effective anisotropy constant $\left(\mathrm{K}_{\mathrm{eff}}\right)$ of any spinel ferrite system is related to the both coercivity $\left(\mathrm{H}_{\mathrm{C}}\right)$ and saturation magnetization $\left(\mathrm{M}_{\mathrm{S}}\right)$ by the stated relation $[22,23]$

$$
\mathrm{K}_{\mathrm{eff}}=\frac{\mathrm{H}_{\mathrm{C}} \mathrm{M}_{\mathrm{S}}}{2}
$$

Calculated values of $\mathrm{K}_{\mathrm{eff}}$ for all the samples are tabulated in table 3. The noted gradual reduction in effective anisotropy constant is ascribed to the reduction in both saturation magnetization as well as coercive field at $300 \mathrm{~K}$ with increasing vanadium content.

\subsection{Absorption spectra studies}

Room temperature optical absorption spectrum of vanadium ions doped nickel ferrite nanoparticles was registered by Uv-Visible spectrometer in the range of $200 \mathrm{~nm}$ to $900 \mathrm{~nm}$. It is already reported that soft bulk spinel cubic nickel ferrite displays exceptional semiconducting feature along with an indirect band gap near $1.65 \mathrm{eV}[24,25]$. We estimate the value of indirect optical band gap and its variation with the slow introduction of vanadium ions in nanocrystalline nickel ferrites. Generally the indirect band gap of any spinel ferrite is obtained by Tauc relation, which is shown below $[10,12,26]$

$$
\alpha(v) . h v \approx C\left(h v-E_{p}\right)^{r}
$$

where ' $\mathrm{C}$ ' indicates an arbitrary constant, $\mathrm{E}_{\mathrm{p}}$ signifies the band gap of the compound, ' $\alpha$ ' represents the absorption coefficient and ' $r$ ' corresponds to an arbitrary index. It can acquire values like $0.5,1.5$, 2, 3 etc. Here the values of ' $r$ ' as 0.5 and 1.5 correspond to direct allowed and forbidden optical transition. On other side, 2 and 3 represent the indirect allowed and forbidden optical transition. Absorption coefficient $(\alpha)$ in equation (7) was estimated for all synthesized samples from the absorbance (A) data with the help of following basic relations $[10,12]$

$$
\mathrm{I}=\mathrm{I}_{\mathrm{o}} \mathrm{e}^{-\alpha \mathrm{d}} \quad \text { and } \quad \mathrm{A}=\log _{10}\left(\frac{I_{o}}{I}\right)
$$

Hence $\alpha=2.303\left(\frac{A}{d}\right)$; where ' $\mathrm{d}$ ' implies the width of the cuvette holding the sample. For obtaining the indirect band gap $\left(\mathrm{E}_{\mathrm{p}}\right)$ for entire nanoferrite samples, a plot of $(\alpha h v)^{1 / 2}$ versus hu was obtained for each sample and is depicted in figure 5. The indirect allowed optical band gaps $\left(\mathrm{E}_{\mathrm{p}}\right)$ were found as $1.66 \mathrm{eV}, 1.72 \mathrm{eV}, 1.73 \mathrm{eV}$ and $1.75 \mathrm{eV}$ for $\mathrm{V}-00, \mathrm{~V}-05, \mathrm{~V}-10$ and $\mathrm{V}-15$ respectively in accordance with increasing vanadium percentage. Indirect band gap was increased for higher vanadium ions content samples. The nano-size effect of the ferrite particles is responsible for observed increment in optical band gap with respect to the bulk form. Generally, the overlap of atomic orbitals remarkably reduces in nanoregime. Hence the width of several electronic bands decreases which results in significant enhancement in band gap [27]. Due to the blue shift in optical band gap and good 
absorption properties, all these prepared ferrite samples can be utilized to eliminate the red and infrared region of electromagnetic spectrum.

\subsection{AC conductivity measurement}

Charge conduction process of soft spinel cubic ferrites can be visualized by measuring the frequency (for AC conductivity) dependent or temperature (for DC conductivity) dependent electrical conductivity. Because of insignificant electrical conductivities, usually spinel cubic ferrites have been used extensively in various microwave applications [28]. Electrical conductivity $\left(\sigma_{t}\right)$ of any material consists of two different parts i.e. DC conductivity and AC conductivity. Overall electrical conductivity for spinel ferrites can be written as [27, 28, 29]

$$
\sigma_{\mathrm{t}}(\mathrm{T}, \omega)=\sigma_{\mathrm{dc}}(\mathrm{T})+\sigma_{\mathrm{ac}}(\mathrm{T}, \omega)
$$

where frequency independent $\sigma_{\mathrm{dc}}$ part implies the DC component of electrical conductivity. $\sigma_{\mathrm{dc}}$ is a temperature dependent term in overall electrical conductivity which generates usually due to the band conduction of charge carriers. The other component in overall electrical conductivity $\sigma_{\mathrm{ac}}$ corresponds to the ac part, which is both temperature as well as applied field frequency dependent term [28]. The hopping of electrons is responsible for observing $\mathrm{AC}$ component in overall electrical conductivity for spinel ferrites. The AC conductivity usually obeys a power law as follows [27, 29]

$$
\sigma_{\mathrm{ac}}(\mathrm{T}, \omega)=\alpha(\mathrm{T}) \omega^{\mathrm{n}}
$$

where $\alpha(T)$ is a constant term, which is temperature dependent. It takes a fixed value for a fixed temperature and a fixed composition, ' $n$ ' represents an exponent which is dimensionless. It attains a value ranging from 0 to 1 . For $n=0$ the electrical conduction is purely a DC conduction $[29,30]$. The room temperature logarithmic curve between AC component of electrical conductivity and field frequency for entire synthesized ferrite samples is displayed in figure 6. Slope of the straight-line curve provides the value of the exponent whereas the intercept on vertical axis is directly related to the constant ' $\alpha$ '. Estimated values of exponent ' $n$ ' were seen within the range of 0.13 to 0.21 for entire prepared nanosized ferrites which also proved that the hopping of charge carriers at $300 \mathrm{~K}$ is the primary conduction procedure $[29,30]$.

\subsection{Dielectric properties studies}

For evaluating the frequency dependent dielectric responses at room temperature, a disc-like pellet of each sample was prepared using a pelletizer. An applied field frequency ranging from $100 \mathrm{~Hz}$ to 10 $\mathrm{MHz}$ was used for impedance measurement. It is well known that the dielectric constant of any 
insulating compound is a complex number comprising of real and imaginary units. It basically discloses the charge storage capacity of a specific material. The dielectric constant can be described as $[28,29]$

$$
\varepsilon(\omega)=\varepsilon^{\prime}(\omega)-i \varepsilon^{\prime \prime}(\omega)
$$

where $\varepsilon^{\prime}(\omega)$ is real part of the dielectric constant which is a field frequency as well as temperature dependent term. It also signifies the ability of storing energy of a dielectric material. The imaginary part $\varepsilon^{\prime \prime}(\omega)$ is directly related to the energy dissipation in any dielectric material [27]. Figure 7 demonstrates the frequency-dependent real unit of permittivity at $300 \mathrm{~K}$ for all prepared nanoferrites. The sample doped with $15 \%$ vanadium ions (V-15) showed the largest value of $\varepsilon^{\prime}(\omega)$ at $100 \mathrm{~Hz}$. As observed from figure 7, the real unit of dielectric constant was enhanced gently with increasing vanadium ions in nano-sized nickel ferrites. It was also found that the real component of permittivity achieved a large value at $100 \mathrm{~Hz}$ and then decreased slowly with the enhancement of applied frequency. This behavior is ascribed to the defects in grain boundaries together with point defects in the samples. The real component $\varepsilon^{\prime}(\omega)$ collapses to zero at high frequency [28, 29]. Normally the charge conduction mechanism in spinel cubic ferrites structure is the hopping of charge carriers (electrons) between cationic sites. Significant losses in polarizations due to the existence of grain boundaries, dopant ions, vacancies as well as defects in nanosized spinel ferrites were also liable for the noticed reduction in dielectric constant. Hence for spinel nanoferrites, usually a high value of permittivity is noticed at low frequency whereas it drops down to almost zero at high frequency [30].

\subsection{Cole-Cole plot analysis}

Following Koop's theory, the emergence of dielectric nature in spinel cubic ferrites is attributed to significant contribution of conducting grains and comparatively less conducting grain boundaries [31]. Generally at low frequency, grain boundaries become more efficient compared to conducting grains in determining the dielectric responses for nanosized spinel ferrites. For distinguishing the effective contributions of grain boundaries and grains in the overall dielectric properties, Cole-Cole plot is an extensively accepted method [32]. For the drawing of Cole-Cole plot, the real and imaginary components of dielectric constant were utilized and dielectric modulus was calculated using the stated relations $[10,27]$

$$
\begin{aligned}
& M^{\prime}(\omega)=\frac{\varepsilon^{\prime}(\omega)}{\varepsilon^{\prime}(\omega)^{2}+\varepsilon^{\prime \prime}(\omega)^{2}} \\
& M^{\prime \prime}(\omega)=\frac{\varepsilon^{\prime \prime}(\omega)}{\varepsilon^{\prime}(\omega)^{2}+\varepsilon^{\prime \prime}(\omega)^{2}}
\end{aligned}
$$


A plot between the real and imaginary units of dielectric modulus in a varying frequency domain is familiar as Cole-Cole plot. Figure 8 illustrates the Cole-Cole plots of all vanadium doped nickel ferrite nanocrystals. Both the V-00 and V-05 ferrite samples exhibited a single broad semicircle while rest of two samples V-10 and V-15 revealed two semicircles of different radii. Basically, the first semicircle near the origin represents the contribution of grain boundaries while the second semicircle far from the origin signifies the contribution of conductive grains [32, 33]. With the increment of vanadium ions concentration in nickel nanoferrites, the conductive grains became more active in comparison to grain boundaries at room temperature. Emergence of a single semi-circular arc for V00 and V-05 samples in the Cole-Cole plot verified that the influences of non-conductive grain boundaries dominated over the grains. The effect of conductive grains for $\mathrm{V}-15$ was more prominent in comparison to all other samples. The reduction in radius of the semicircles with increasing vanadium ions content also reflected the increment of DC conductivity in the synthesized samples $[28,32]$.

\section{Conclusion}

In brief, single-phase vanadium substituted nanocrystalline nickel ferrite samples were fabricated via soft chemical co-precipitation method. Generation of pure cubic spinel crystal structure for all prepared samples were verified by x-ray powder diffraction profiles. Average crystallite diameter ranged from $05 \mathrm{~nm}$ to $12 \mathrm{~nm}$ was observed for all samples. Lattice parameter reduced for higher vanadium ions content samples. A compressive microstrain within the nanocrystals was detected from $\mathrm{W}-\mathrm{H}$ plots for entire samples. HRTEM images were also found in good agreement with mean crystallite sizes. Both the coercivity and saturation magnetization were decreased at room temperature with increasing dopant percentage. Indirect optical band gaps were found to increase with increasing vanadium ions percentage in Tauc plots. Due to the excellent absorption near the red and infrared zones, all these nanoparticles are useful to eliminate the infrared rays. Logarithmic curve of frequency dependent $\mathrm{AC}$ conductivity revealed that the jumping of electrons in between cationic sites was the basic conduction mechanism for all the samples. With increasing vanadium ions percentages, synthesized nanoferrites exhibited excellent dielectric responses at $100 \mathrm{~Hz}$. Significant contribution of grain boundaries in gross impedance were confirmed by Cole-Cole plots. On concluding note, incorporation of vanadium ions in soft nickel nanoparticles modifies several physical properties remarkably.

\section{Author contribution statement}

All the authors contributed equally in this work. 


\section{Declaration of interests}

Authors declare that they have no known competing financial interests or personal relationships that could have appeared to influence the work reported in this paper.

\section{References}

[1] S. B. Darling, S. D. Bader, J. Mater. Chem. 15, 4189-4195 (2005).

[2] S. Kumar, V. Singh, S. Aggarwal, U. K. Mandal, R. K. Kotnala, Mater. Sci. Eng. B 166, 76 (2010).

[3] Alberto P. Guimaraes, Principles of nanomagnetism, Springer, Germany (2009).

[4] G. Bertotti, Hysteresis in magnetism: For Physicists, Material Scientists and Engineers, Academic Press-Elsevier, USA (1998).

[5] J. M. D. Coey, Magnetism and Magnetic Materials, Cambridge University Press, New York (2009).

[6] S. Blundell, Magnetism in Condensed Matter, Oxford University Press, Oxford (2001).

[7] S. B. Narang, K. Pubby, J. Magn. Magn. Mater. 519, 167163 (2021).

[8] R. Valenzuela, Phys. Res. Int. 591839, 1-9 (2012).

[9] N. A. Usov, O. N. Serebryakova, Scien. Report. 10, 13677 (2020).

[10] M. P. Ghosh, S. Kinra, D. Dagur, R. K. Choubey, S. Mukherjee, Phys. Scr. 95, 095812 (2020).

[11] R. H. Kodama, A. Berkowitz, E. McNiff, S. Foner, Phys. Rev. Lett. 77, 394-397 (1996).

[12] M. P. Ghosh, S. Datta, R. Sharma, K. Tanbir, M. Kar, S. Mukherjee, Mater. Sci. Engg. B 263, $114864(2021)$.

[13] R. Mohan, M. P. Ghosh, S. Mukherjee, J. Magn. Magn. Mater. 458, 193-199 (2018).

[14] D. Carta, M. F. Casula, A. Falqui, D. Loche, G. Mountjoy, C. Sangregorio and A.Corrias J. Phys. Chem. C 113, 8606-8615 (2009).

[15] Z. K. Heiba, M. B. Mohamed, A. M. Wahba, M. I. Almalowi, Appl. Phys. A 124, 290 (2018).

[16] Z. K. Heiba, M. B. Mohamed, S. I. Ahmed, J. Magn. Magn. Mater. 441, 409-416 (2017).

[17] V. Manikandan, I. Petrila, S. Kavita, R. S. Mane, J. C. Denardin, S. Lundgaard, S. Juodkazis, S. Vigneselvan, J. Chandrasekaran, J. Mater. Sci.: Mater. Electron. 31, 16728-16736 (2020). 
[18] M. P. Ghosh, S. Mukherjee, J. Am. Ceram. Soc. 102, 7509-7520 (2019).

[19] Aakash, P. Nordblad, R. Mohan, S. Mukherjee, J. Magn. Magn. Mater. 441, 710 (2017).

[20] R. Sharma, P. Thakur, M. Kumar, P. Sharma, Ceram Inter. 43(16), 13661-13669 (2017).

[21] M. P. Ghosh, S. Sharma, H. K. Satyapal, K. Tanbir, R. K. Singh, S. Mukherjee, Mater. Chem. Phys. 241, 122383 (2020).

[22] B. D. Cullity, C. D. Graham, Introduction to Magnetic Materials, (chapter 7) Wiley publisher (2009).

[23] M. P. Ghosh, S. Mukherjee, J. Magn. Magn. Mater. 498, 166185 (2020).

[24] B. S. Holinsworth, D. Mazumder, H. Sims, Q. C. Sun, M. K. Yurtisigi, S. K. Sarker, A. Gupta, W. H. Buther, J. L.Musfeldt, Appl. Phys. Lett.103, 082406 (2013).

[25] Q. C. Sun, H. Sims, D. Mazumder, J. X. Ma, B. S. Holinsworth, K. R. O. Neal, G. Kim G, W. H. Butler, A. Gupta, J. L. Musfeldt, Phys. Rev. B. 86, 205106 (2012).

[26] S. Singhal, S. Bhukal, J. Singh, K. Chandra, S. Bansal, J. Nanotechn. 930243, 1-6 (2011).

[27] K. Tanbir, M. P. Ghosh, R. K. Singh, S. Mukherjee, J. Mater. Sci.: Mater. Electron. 31, 35293538 (2020).

[28] Aakash, M. P. Ghosh, S. Mukherjee, Appl. Phys. A 125, 853 (2020).

[29] Z. Z. Lazarevic, C. Jovalekic, D. L. Sekulic, A. Milutinovic, S. Balos, M. Slankamenac, N. Z. Romcevic, Mater. Resear. Bullet. 48, 4368-4378 (2013).

[30] D. Varshney, K.Verma, Mater. Chem. Phys. 140, 412-418 (2013).

[31] C. G. Koops, Phys. Rev. 83, 121 (1951).

[32] H. M. T Farid, I. Ahmad, I. Ali, A. Mahmood, S. M. Ramay, Eur. Phys. J. Plus 133, 41 (2018).

[33] K. M. Batoo, M. S. Ansari, Nanoscale Research Letters 7, 112 (2012).

\section{List of tables}

Table 1: Represents several microstructural parameters and Rietveld refinement factors of all the nanoferrites.

Table 2: Contains hopping lengths of all the nanoferrites.

Table 3: Represents several magnetic parameters obtained at $300 \mathrm{~K}$ for all the samples. 


\section{List of figures}

Figure 1: $\mathrm{XRD}$ patterns of $\mathrm{NiV}_{\mathrm{x}} \mathrm{Fe}_{2-\mathrm{x}} \mathrm{O}_{4}(\mathrm{x}=0.00,0.05,0.10$ and 0.15$)$ samples.

Figure 2: Williamson-Hall (W-H) plots of all the ferrite nanoparticles.

Figure 3 (a): HRTEM image of V-00 sample.

Figure 3(b): HRTEM image of V-15 sample.

Figure 3(c): Crystallographic lattice plane image of V-00 sample.

Figure 3(d): SAED pattern of V-00 sample.

Figure 4: Room temperature M-H curves of all the samples.

Figure 5: Tauc plots of $\mathrm{NiV}_{\mathrm{x}} \mathrm{Fe}_{2-\mathrm{x}} \mathrm{O}_{4}(\mathrm{x}=0.00,0.05,0.10$ and 0.15$)$ samples recorded at $300 \mathrm{~K}$.

Figure 6: AC conductivity vs applied frequency in logarithmic scale of all the samples.

Figure 7: Frequency dependent real part of dielectric constant of entire samples.

Figure 8: Cole-Cole plots of all the samples.

\begin{tabular}{|c|c|c|c|c|}
\hline Sample-Id & $\mathrm{V}-00$ & V-05 & $\mathrm{V}-10$ & $\mathrm{~V}-15$ \\
\hline Space group & $\mathrm{Fd} \overline{3} \mathrm{~m}$ & $\mathrm{Fd} \overline{3} \mathrm{~m}$ & $\mathrm{Fd} \overline{3} \mathrm{~m}$ & $\mathrm{Fd} \overline{3} \mathrm{~m}$ \\
\hline \multicolumn{5}{|l|}{ Cell parameters } \\
\hline $\mathrm{a}(\AA)$ & 8.346 & 8.331 & 8.326 & 8.319 \\
\hline $\mathrm{D}(\mathrm{nm})$ & 12 & 06 & 07 & 05 \\
\hline $\begin{array}{l}\text { Compressive } \\
\text { microstrain }\left(\mathrm{X}_{10^{-4}}\right)\end{array}$ & 4.89 & 5.78 & 0.99 & 0.59 \\
\hline \multicolumn{5}{|l|}{ Refinement factors } \\
\hline $\mathrm{R}_{\mathrm{wp}}(\%)$ & 2.03 & 1.98 & 2.11 & 2.07 \\
\hline $\mathrm{R}_{\mathrm{p}}(\%)$ & 1.62 & 1.57 & 1.68 & 1.61 \\
\hline$\chi^{2}$ & 1.09 & 1.08 & 1.18 & 1.04 \\
\hline
\end{tabular}

Table 1

\begin{tabular}{|l|l|l|}
\hline Sample-Id & $\mathrm{S}_{\mathrm{A}}(\AA)$ & $\mathrm{S}_{\mathrm{B}}(\AA)$ \\
\hline $\mathrm{V}-00$ & 3.697 & 2.951 \\
\hline $\mathrm{V}-05$ & 3.691 & 2.945 \\
\hline $\mathrm{V}-10$ & 3.688 & 2.943 \\
\hline V-15 & 3.685 & 2.940 \\
\hline \multicolumn{3}{|c|}{ Table 2} \\
\hline
\end{tabular}




\begin{tabular}{|c|c|c|c|c|}
\hline \multirow[t]{2}{*}{ Sample-Id } & \multicolumn{4}{|c|}{ Magnetic properties } \\
\hline & $\mathrm{M}_{\mathrm{S}}(\mathrm{emu} / \mathrm{g})$ & $\mathrm{H}_{\mathrm{C}}(\mathrm{Oe})$ & $\mu_{\mathrm{T}}\left(\mu_{\mathrm{B}}\right)$ & $\mathrm{K}_{\mathrm{eff}}\left(\mathrm{X} 10^{3} \mathrm{erg} / \mathrm{cm}^{3}\right)$ \\
\hline $\mathrm{V}-00$ & 42.5 & 517.2 & 1.78 & 10.99 \\
\hline V-05 & 32.3 & 192.1 & 1.36 & 3.10 \\
\hline V-10 & 20.4 & 99.1 & 0.85 & 1.01 \\
\hline $\mathrm{V}-15$ & 17.3 & 92.6 & 0.72 & 0.80 \\
\hline
\end{tabular}

Table 3
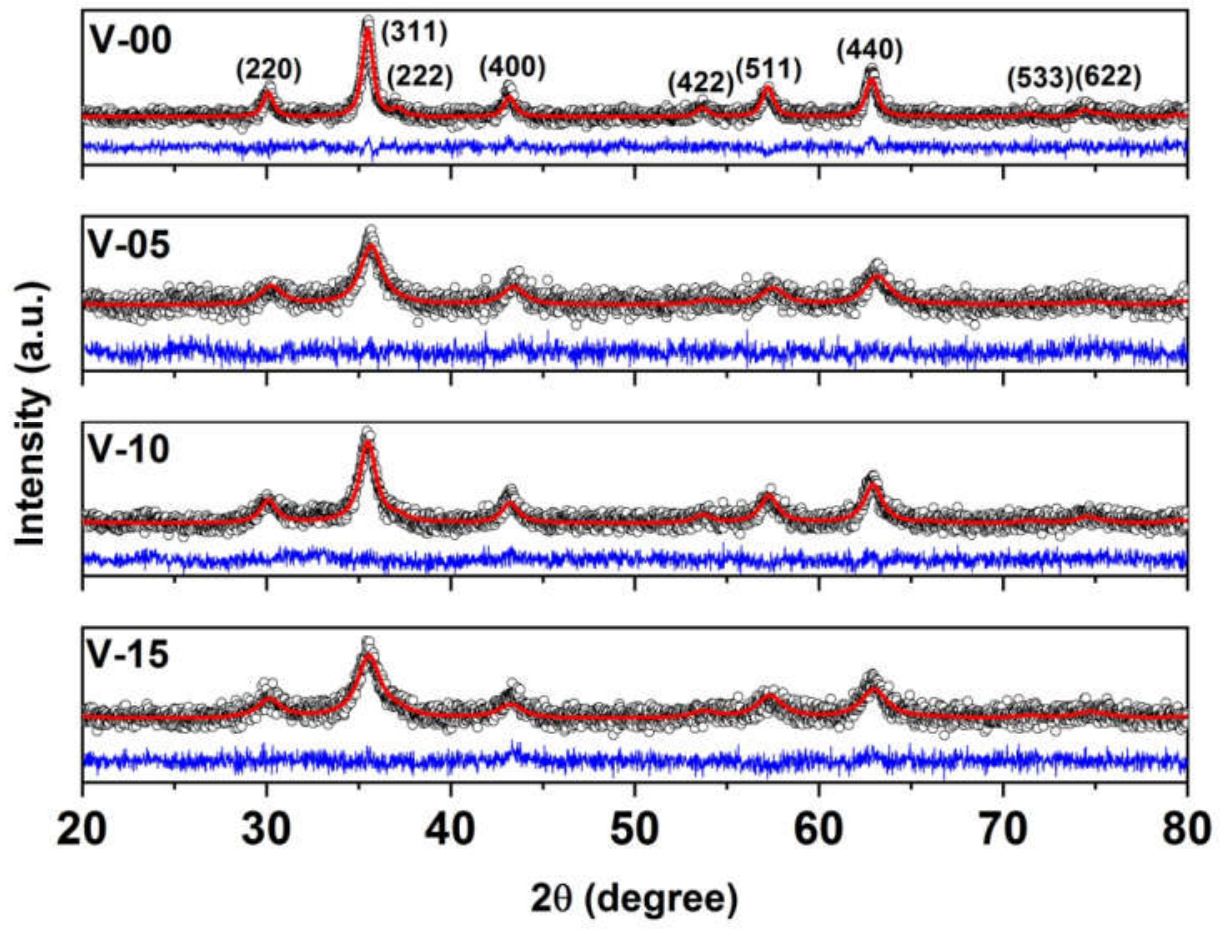

Figure 1 


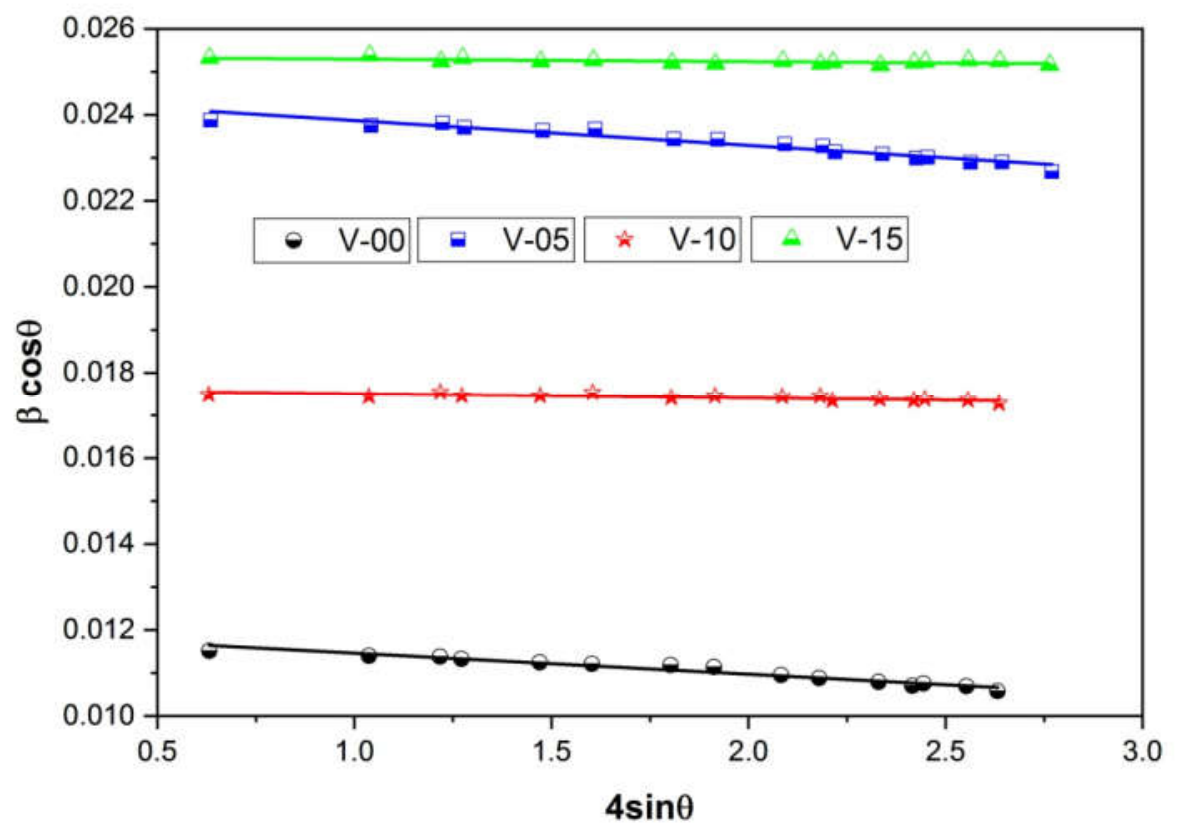

Figure 2

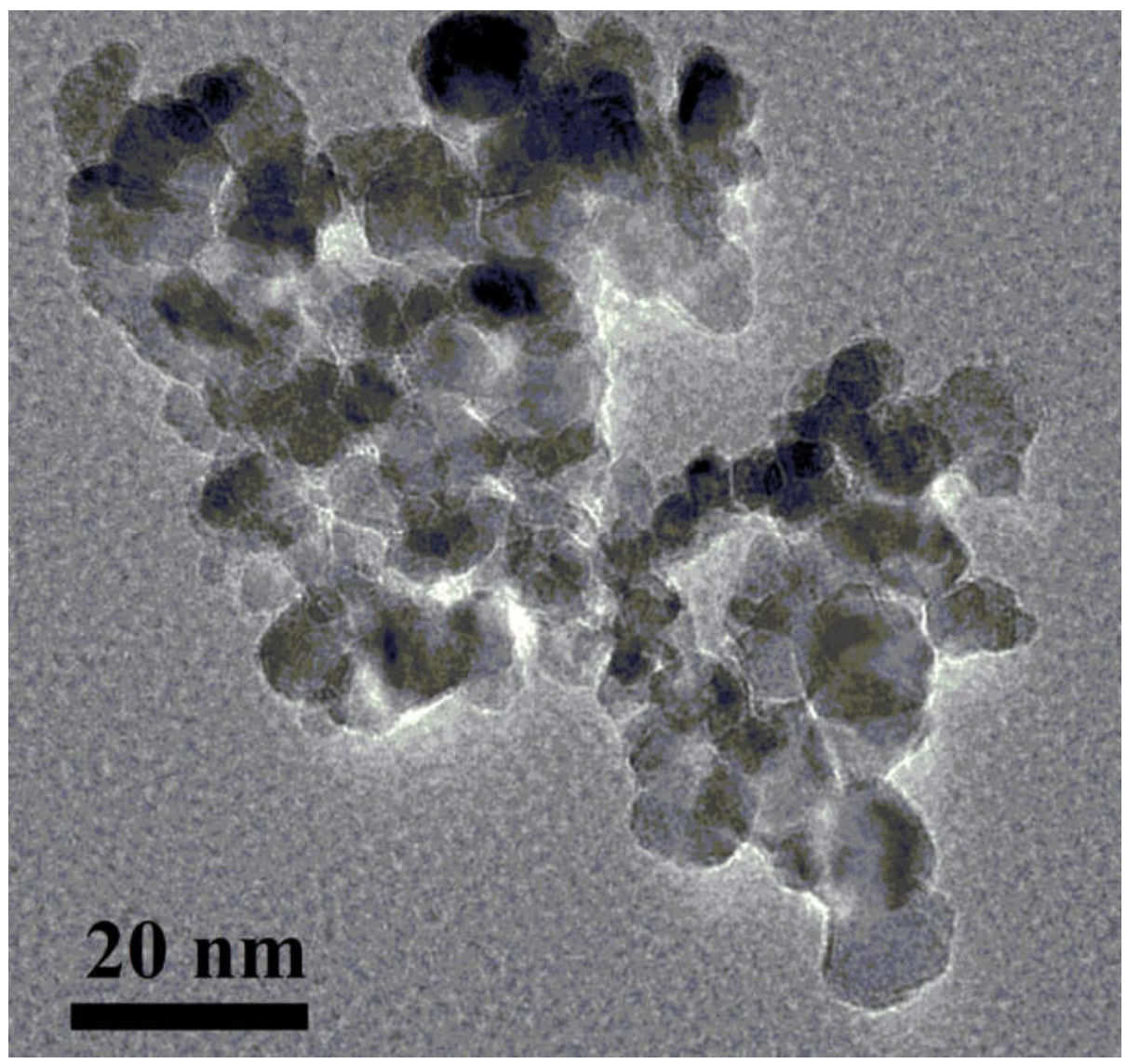

Figure 3(a) 


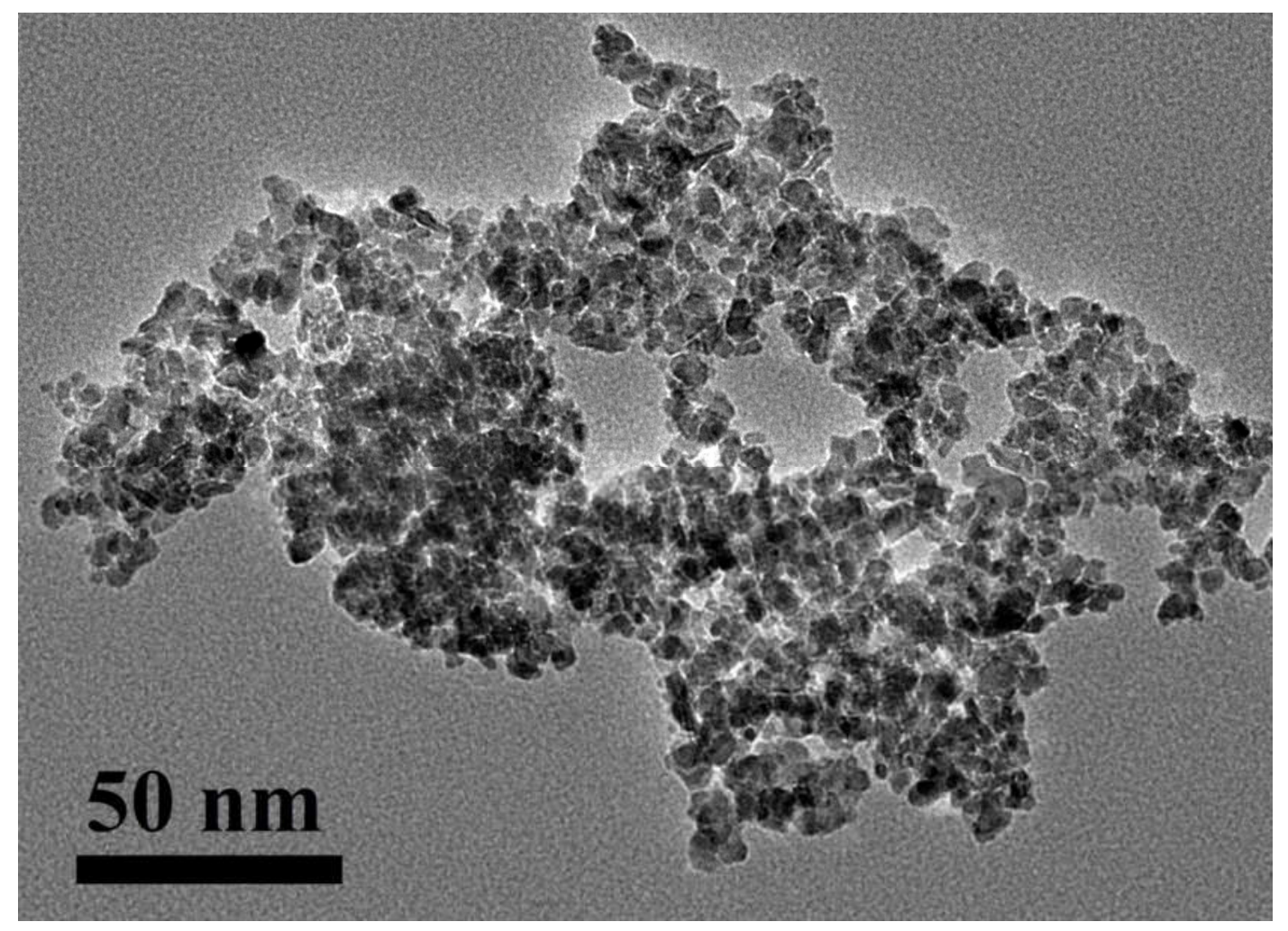

Figure 3(b)

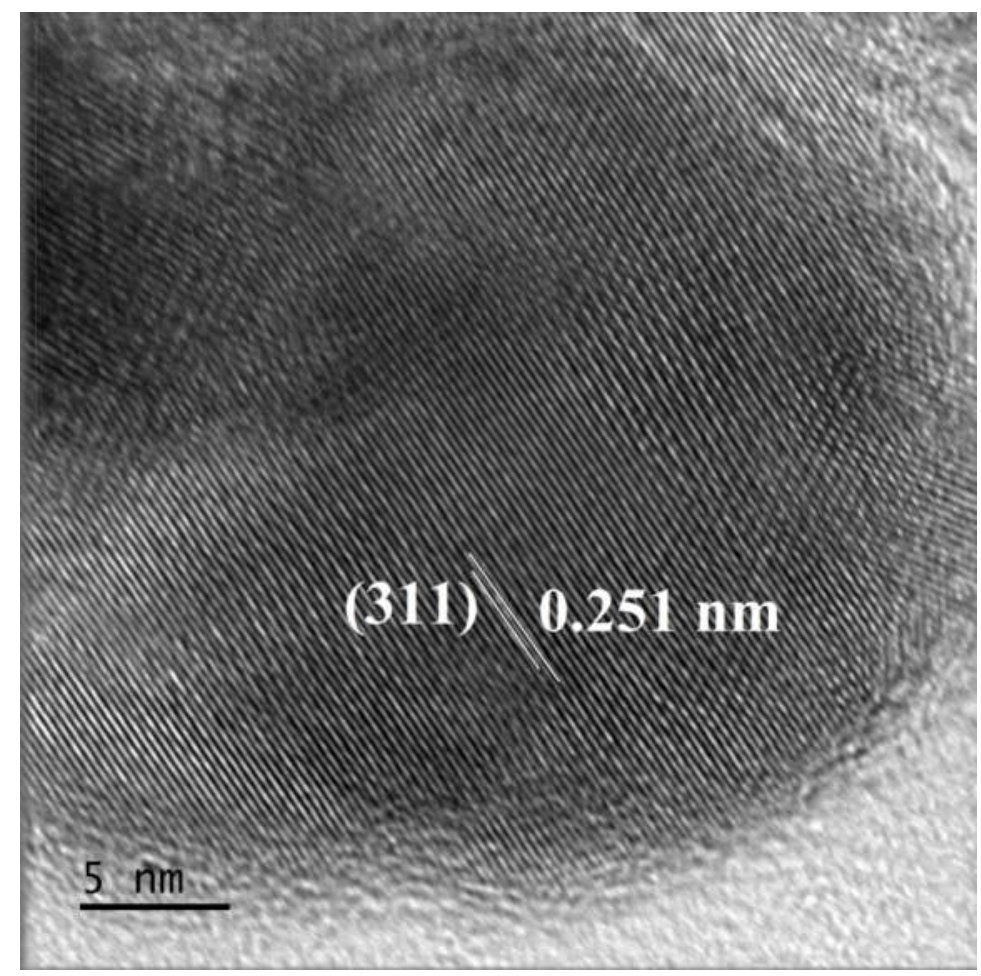

Figure 3(c) 


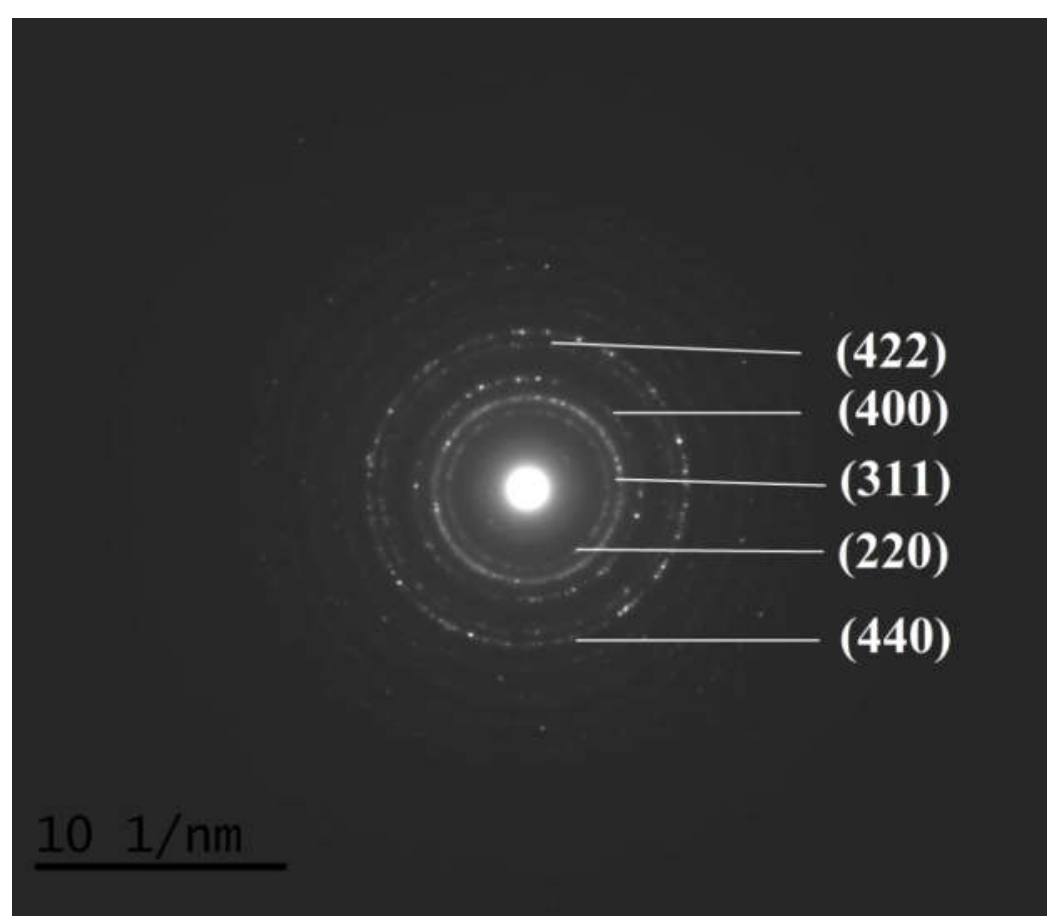

Figure 3(d)

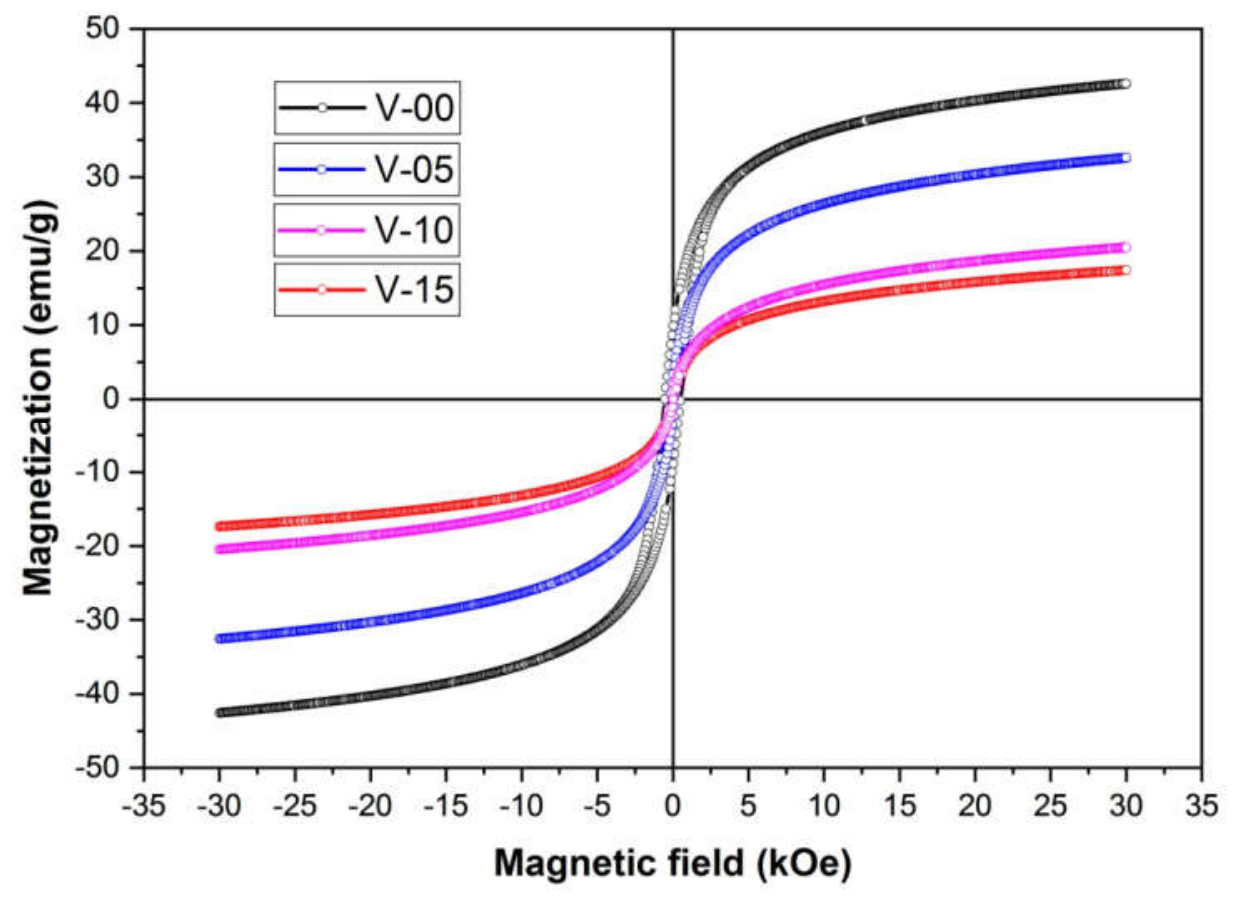

Figure 4 


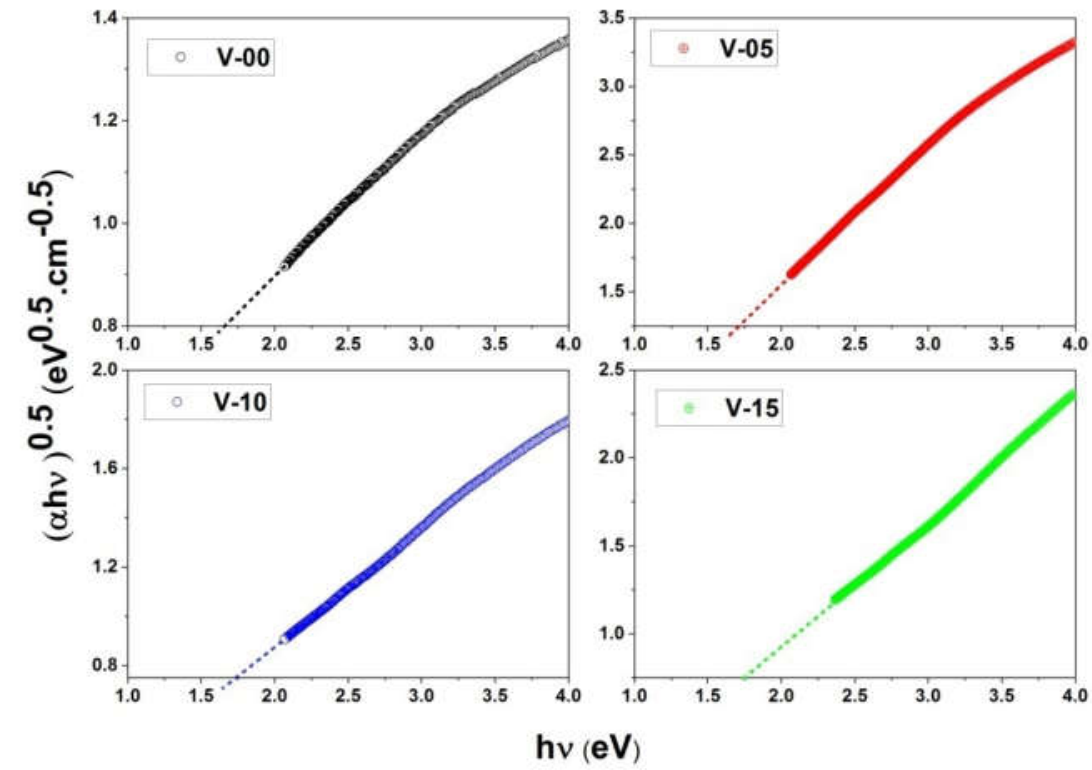

Figure 5

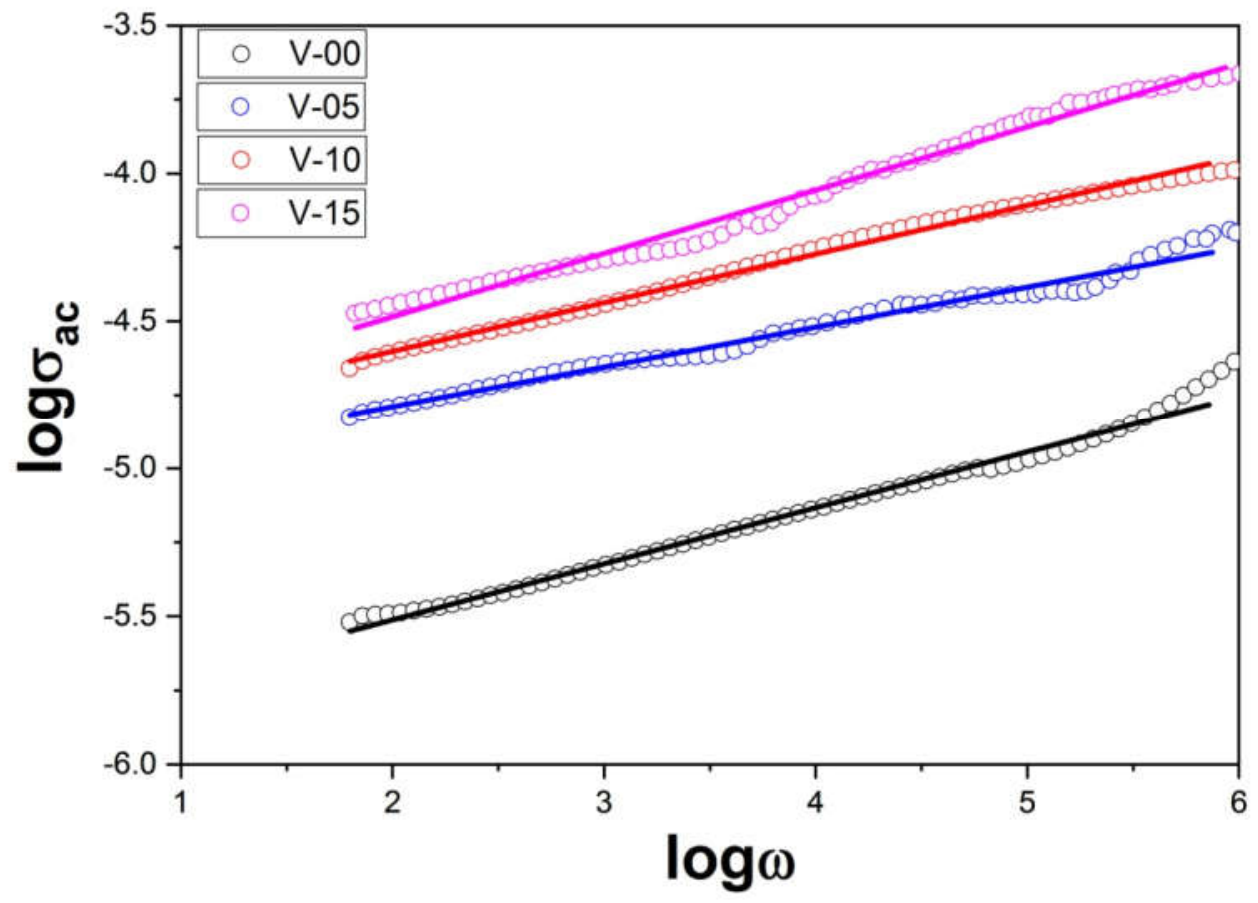

Figure 6 


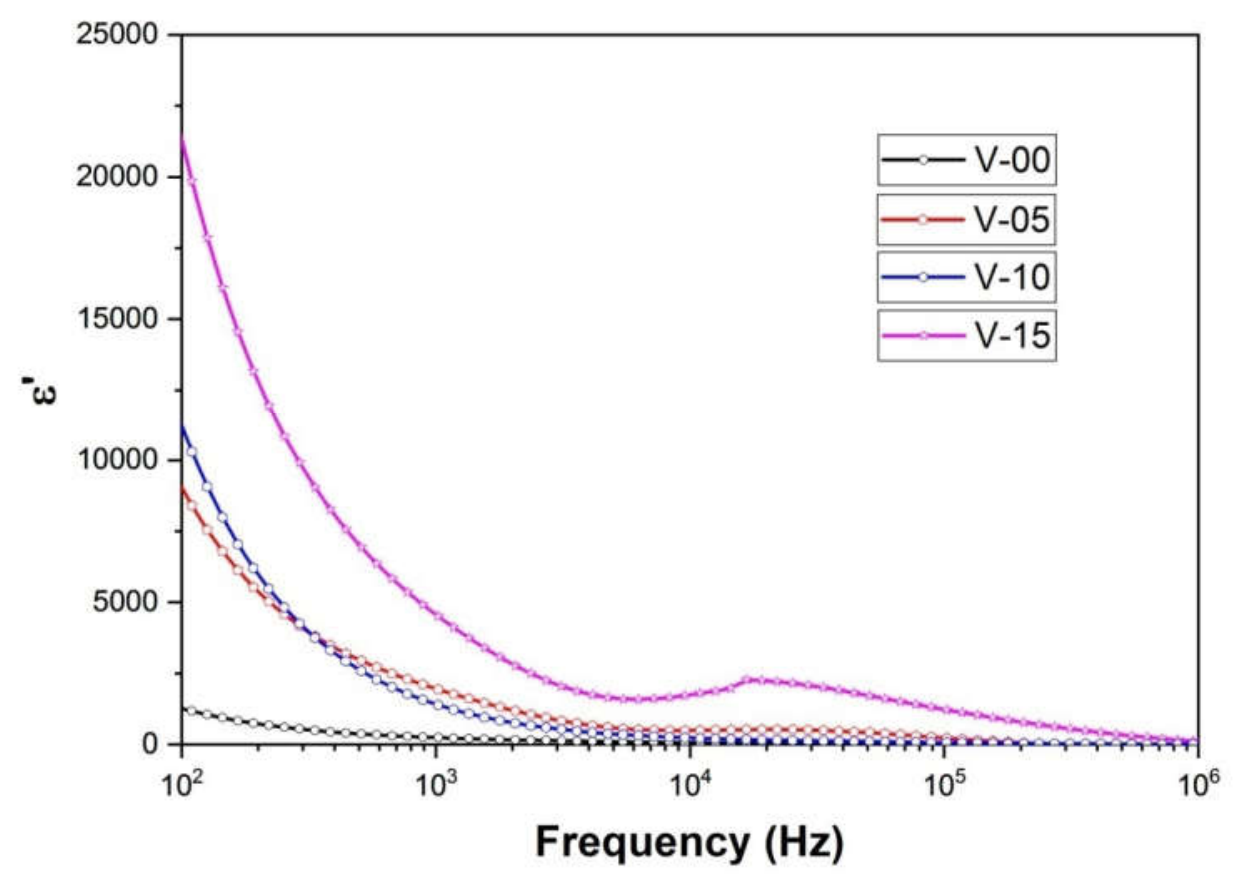

Figure 7

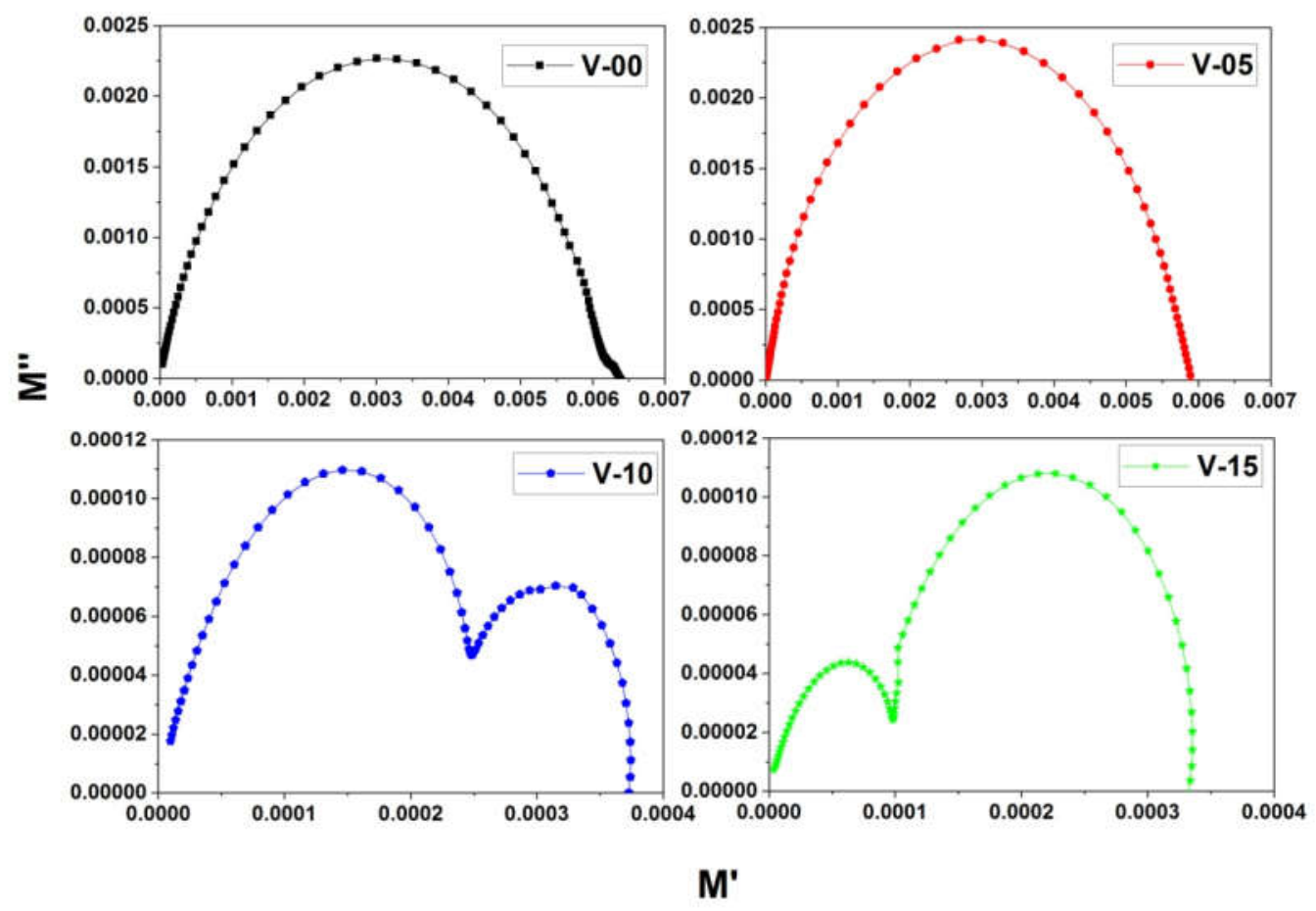

Figure 8 


\section{Figures}
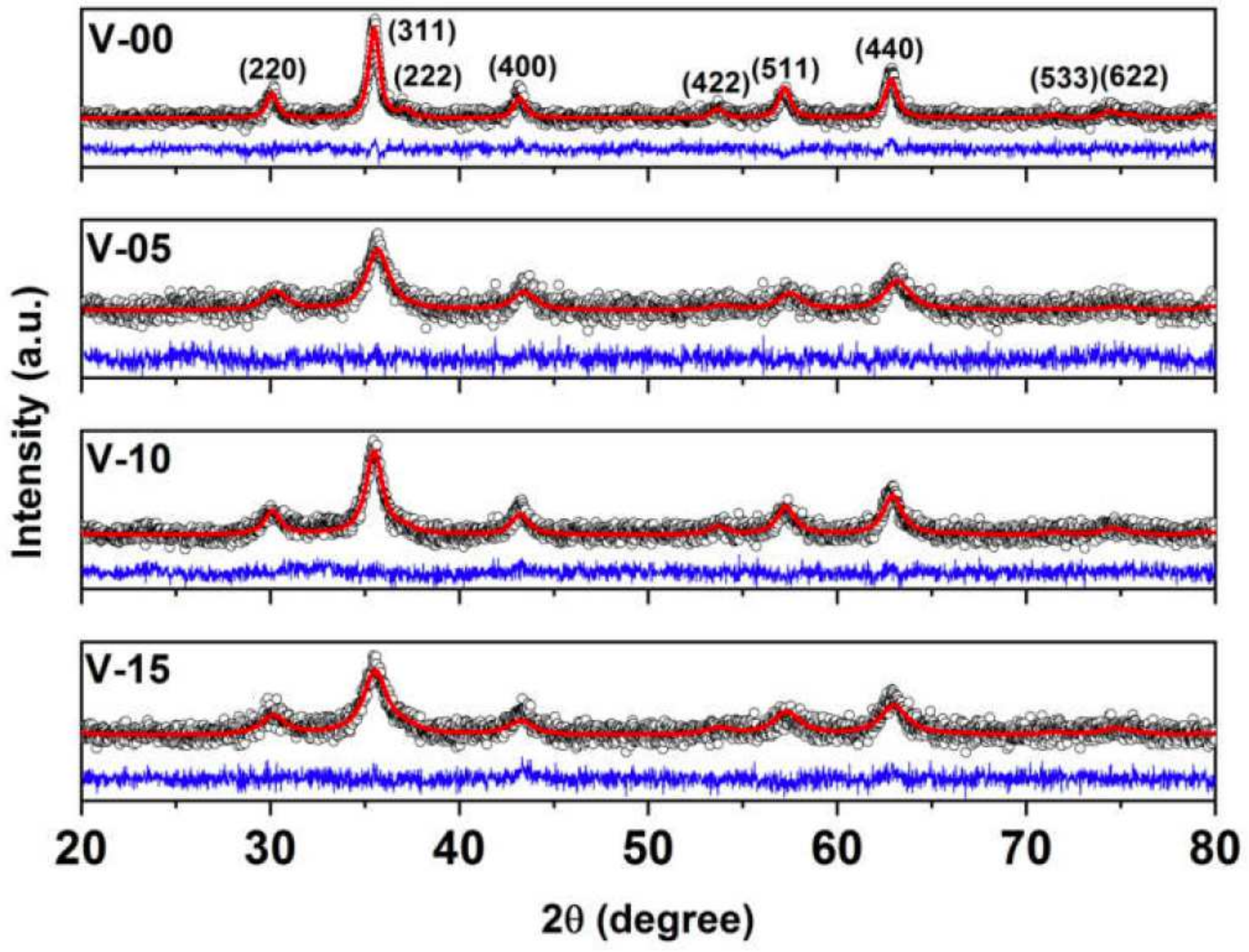

Figure 1

XRD patterns of NiVxFe2-xO4 $(x=0.00,0.05,0.10$ and 0.15$)$ samples 


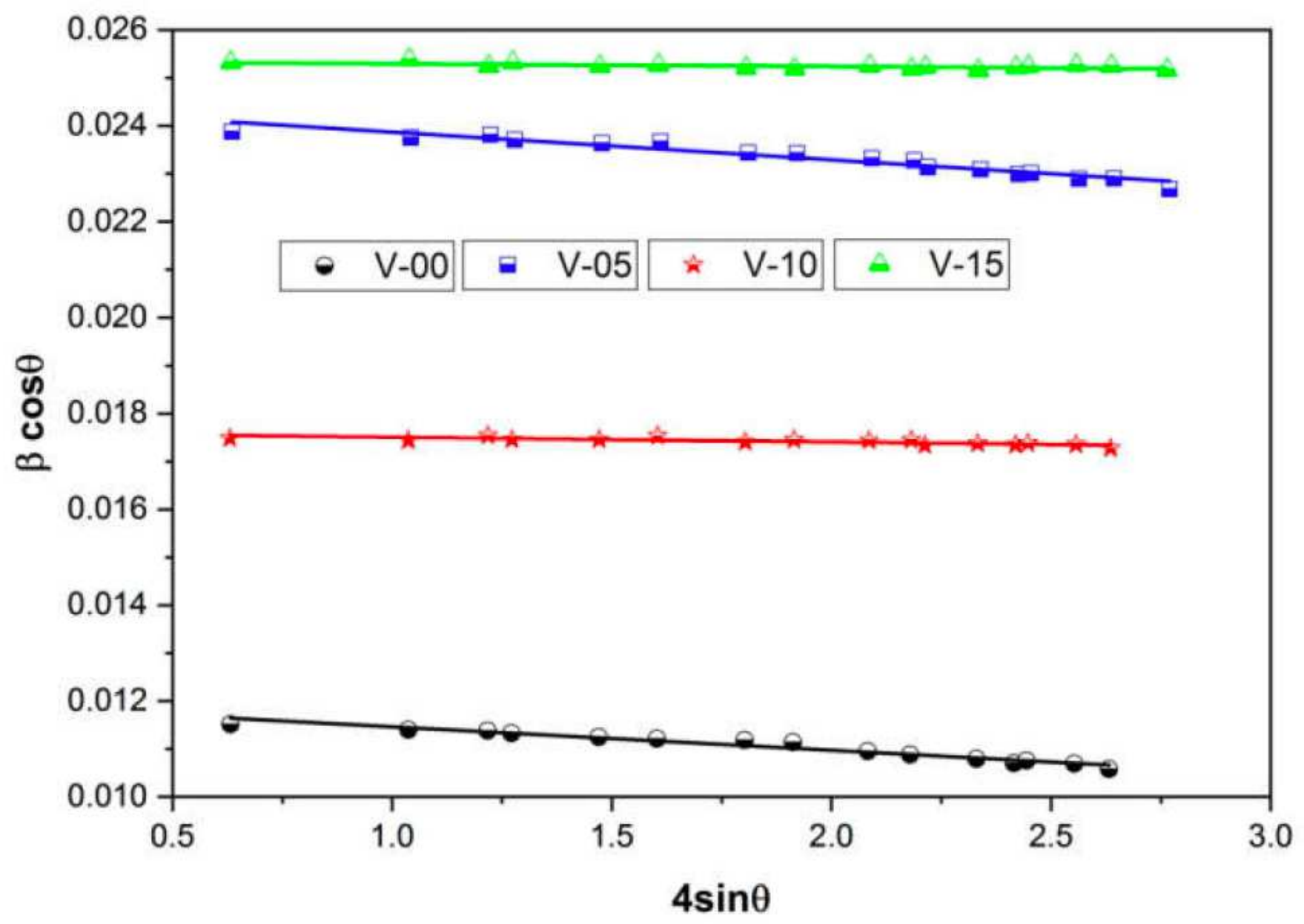

Figure 2

Williamson-Hall (W-H) plots of all the ferrite nanoparticles. 


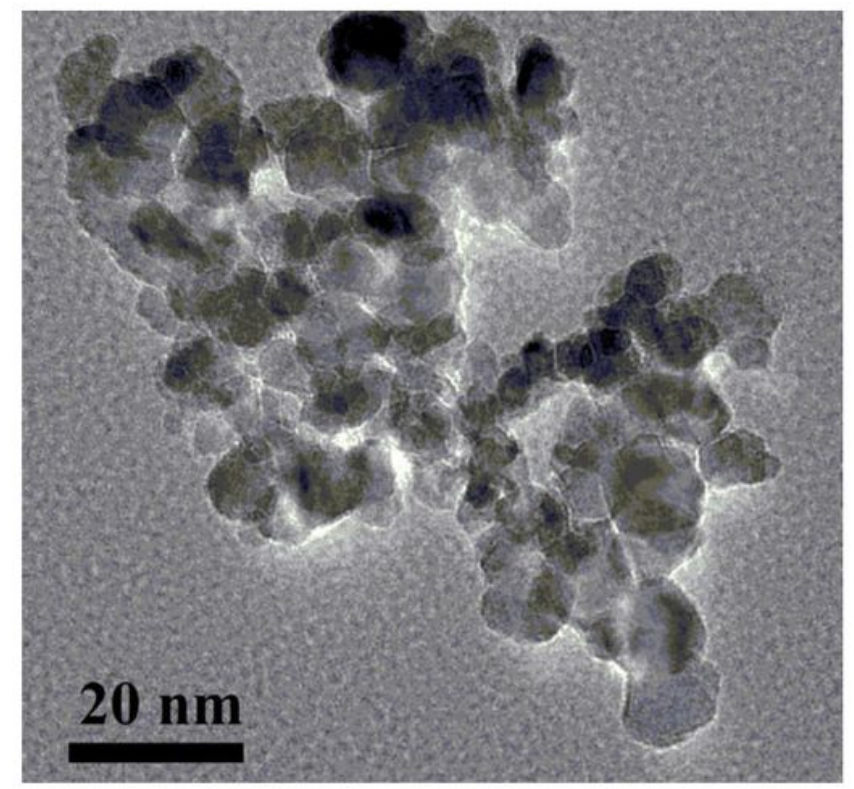

Figure 3(a)

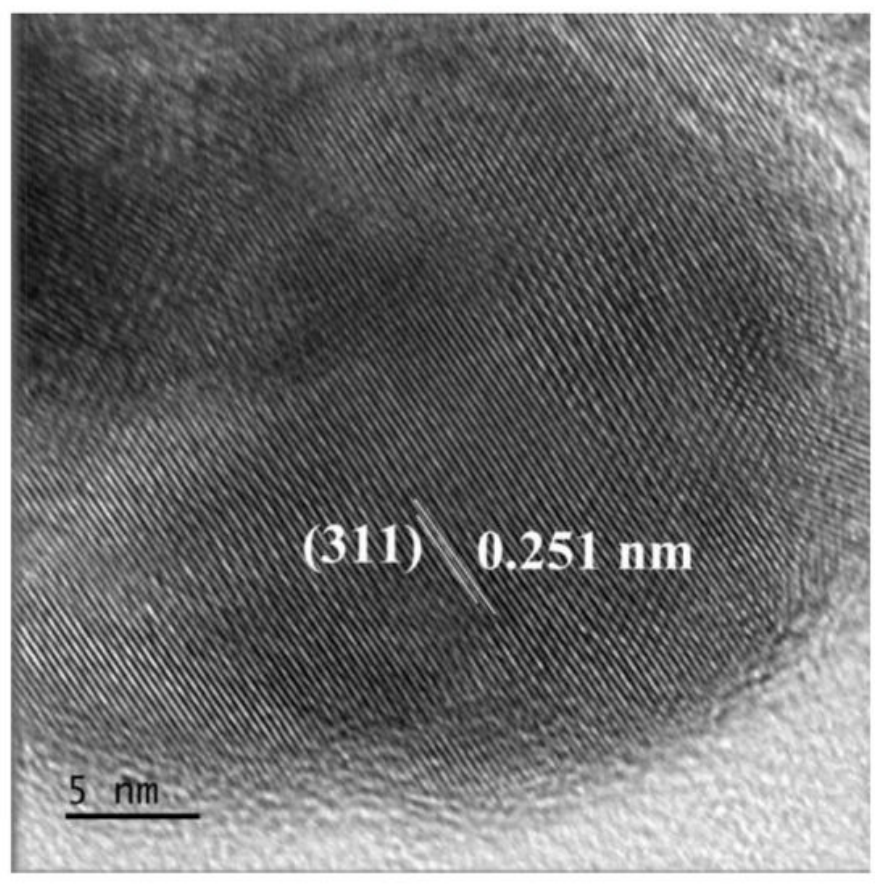

Figure 3(c)

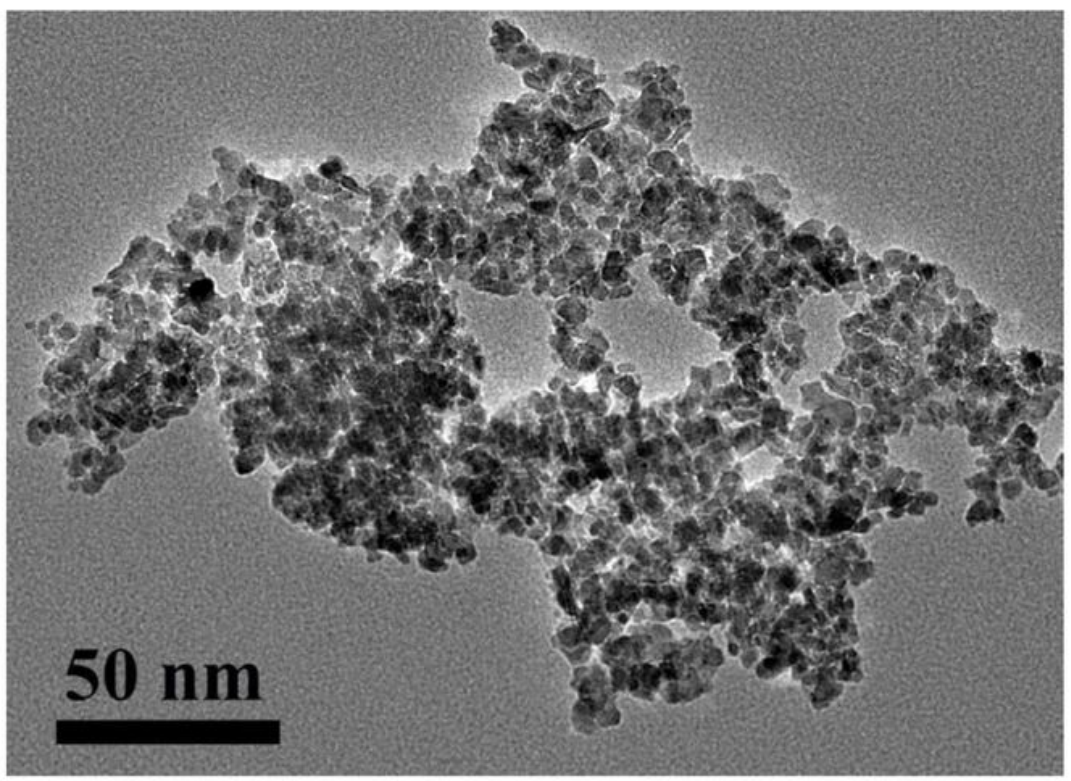

Figure 3(b)

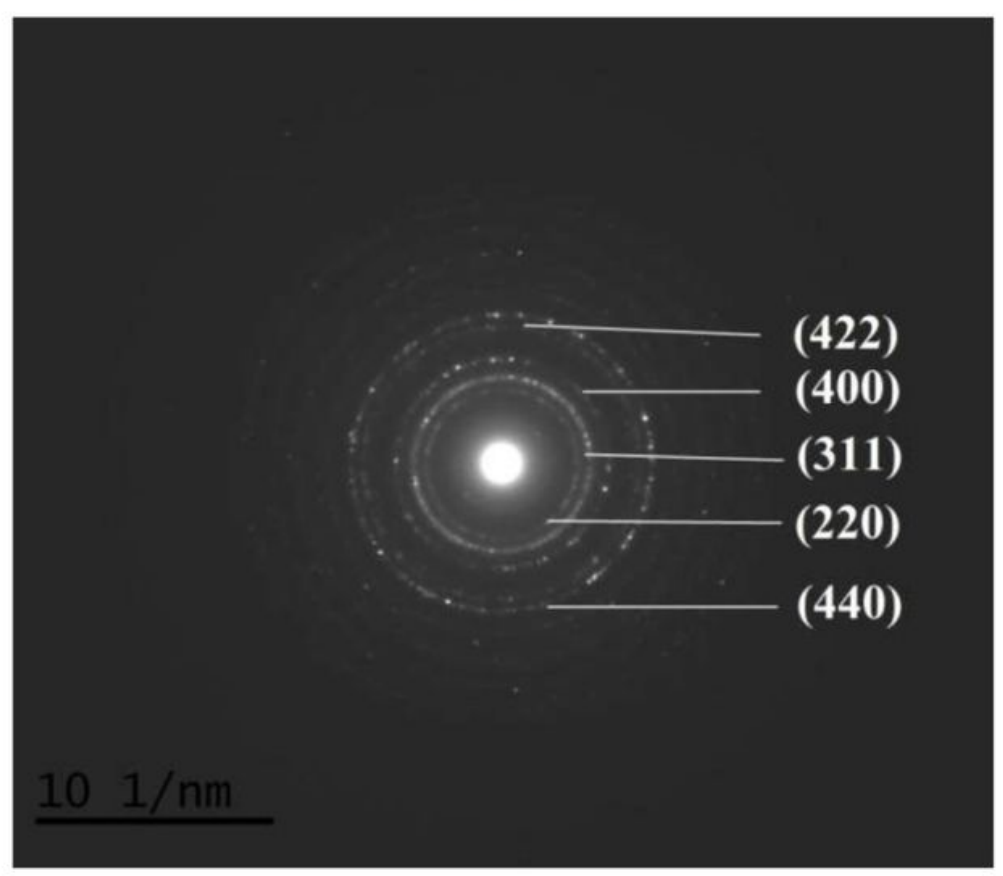

Figure 3(d)

\section{Figure 3}

(a) HRTEM image of V-00 sample. (b) HRTEM image of V-15 sample. (c) Crystallographic lattice plane image of V-00 sample. (d) SAED pattern of V-00 sample. 


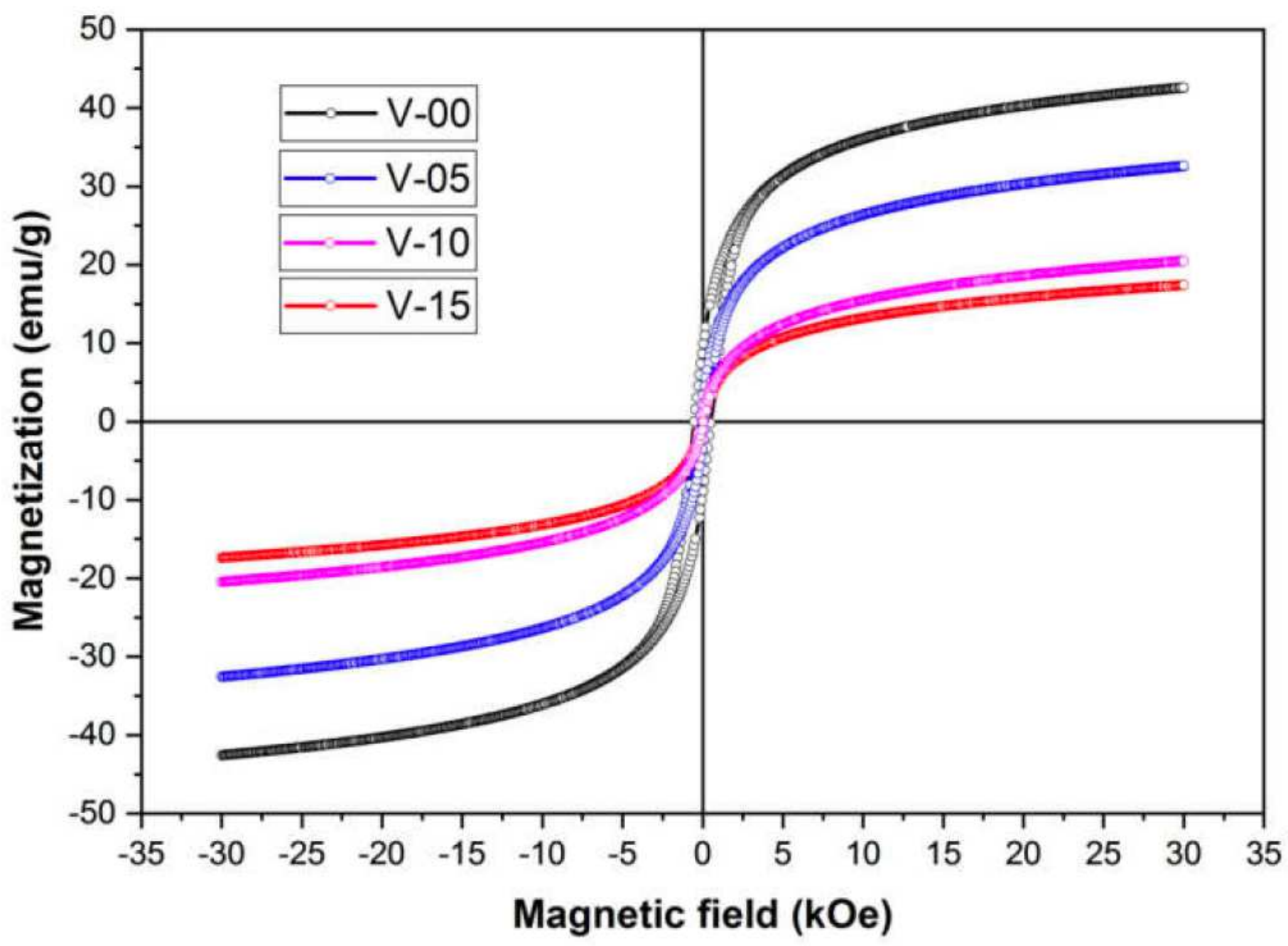

Figure 4

Room temperature $\mathrm{M}-\mathrm{H}$ curves of all the samples. 

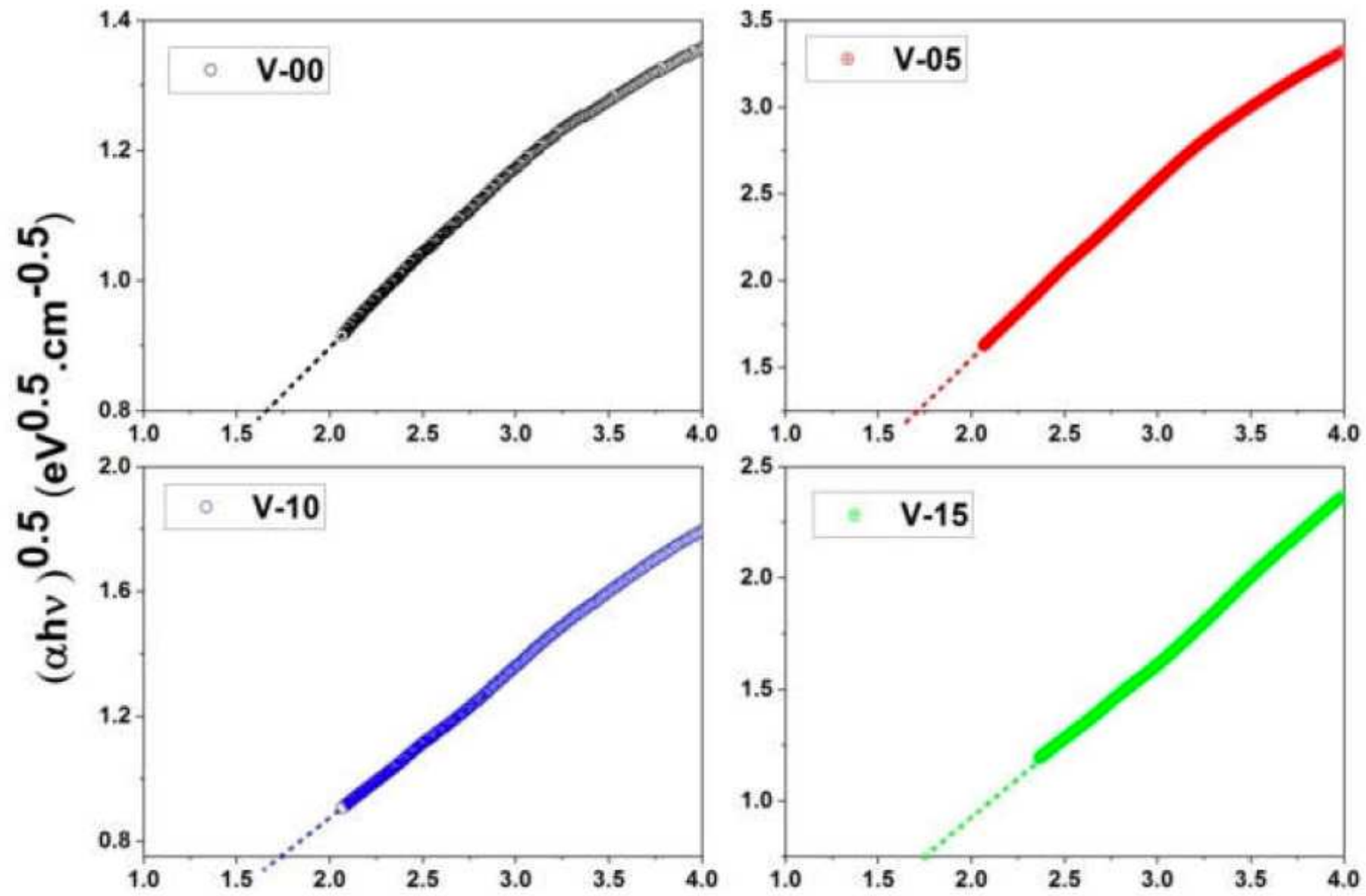

$\mathrm{h} v(\mathrm{eV})$

Figure 5

Tauc plots of NiVxFe2-xO4 ( $x=0.00,0.05,0.10$ and 0.15$)$ samples recorded at $300 \mathrm{~K}$. 


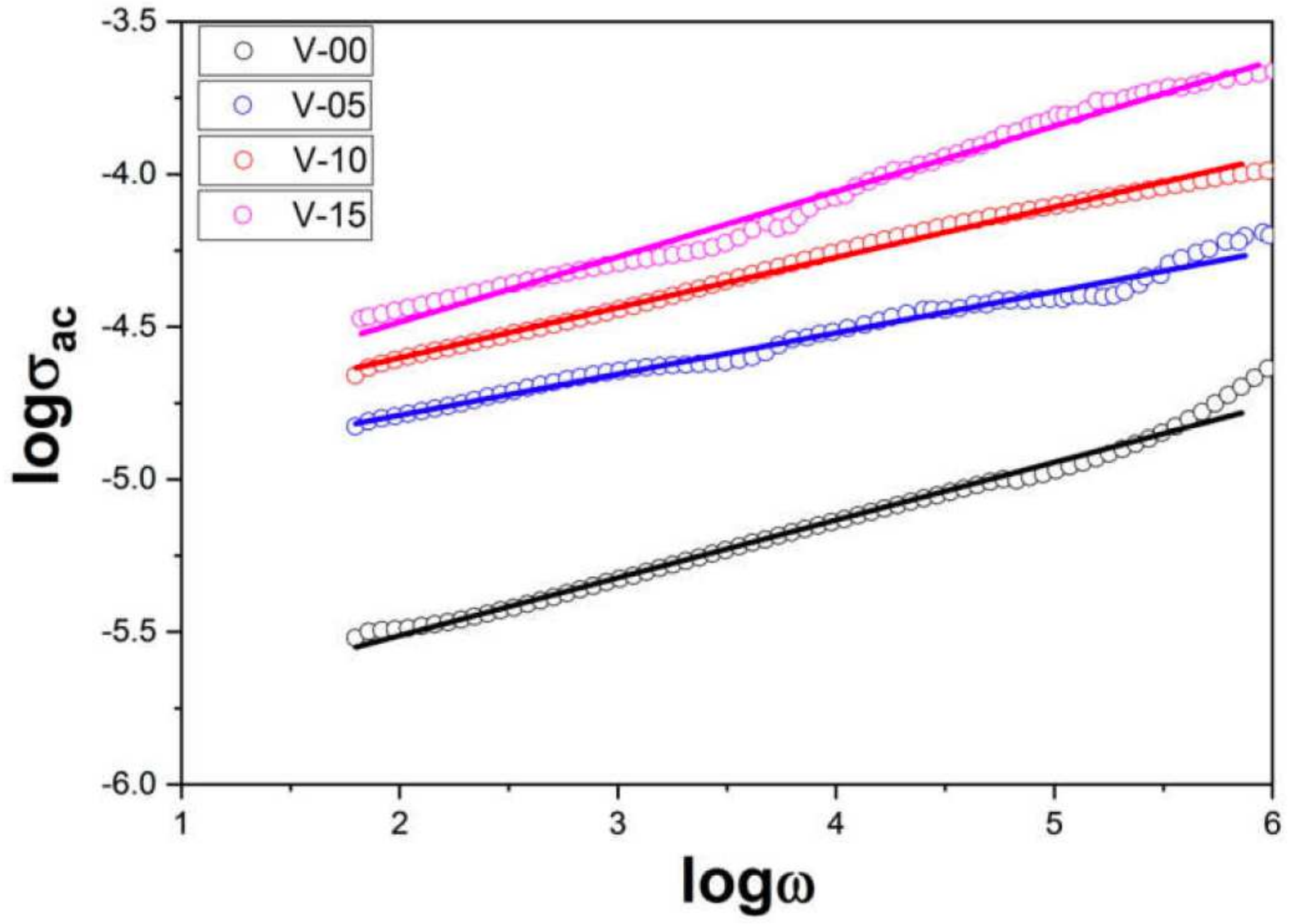

Figure 6

AC conductivity vs applied frequency in logarithmic scale of all the samples. 


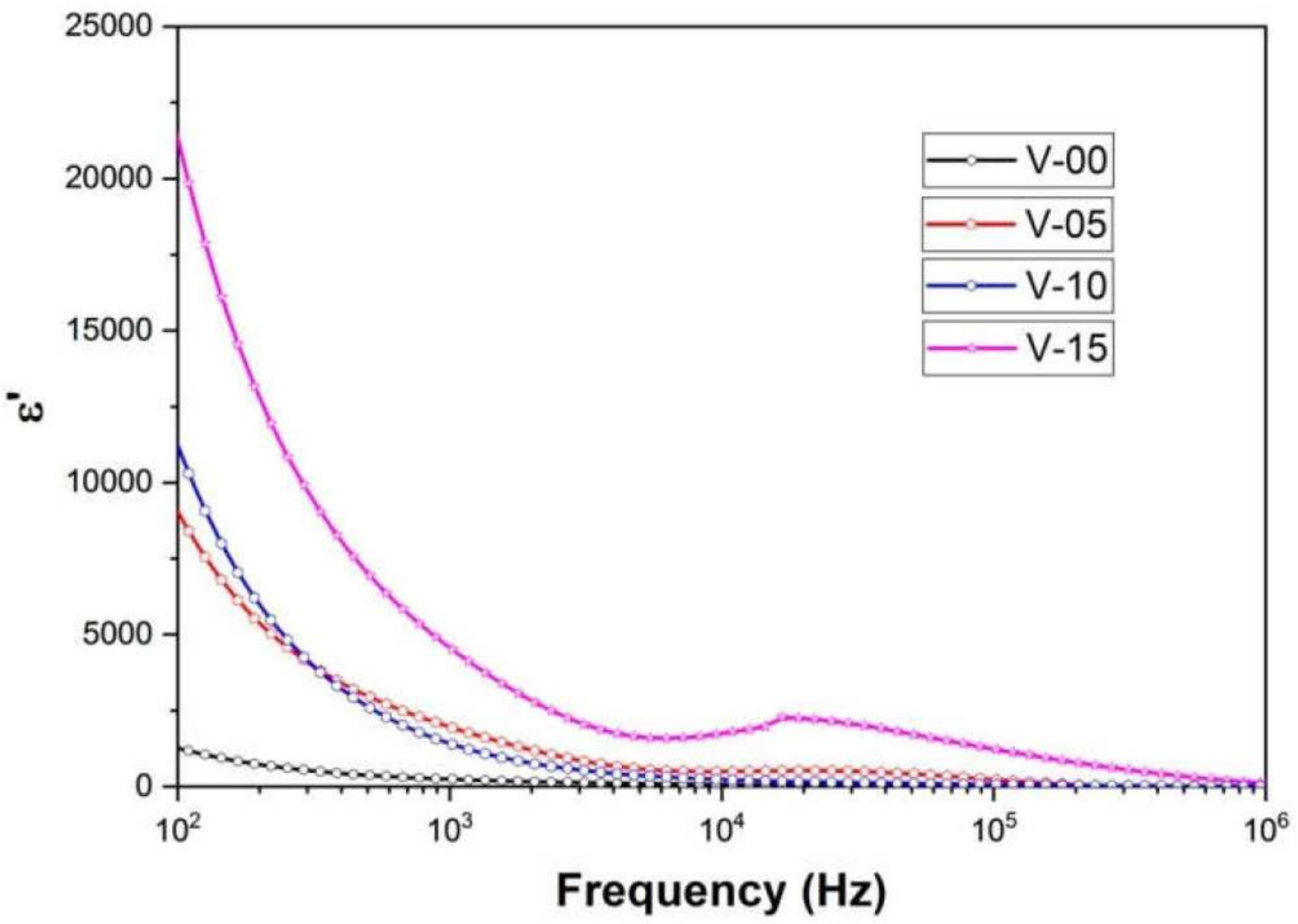

Figure 7

Frequency dependent real part of dielectric constant of entire samples. 

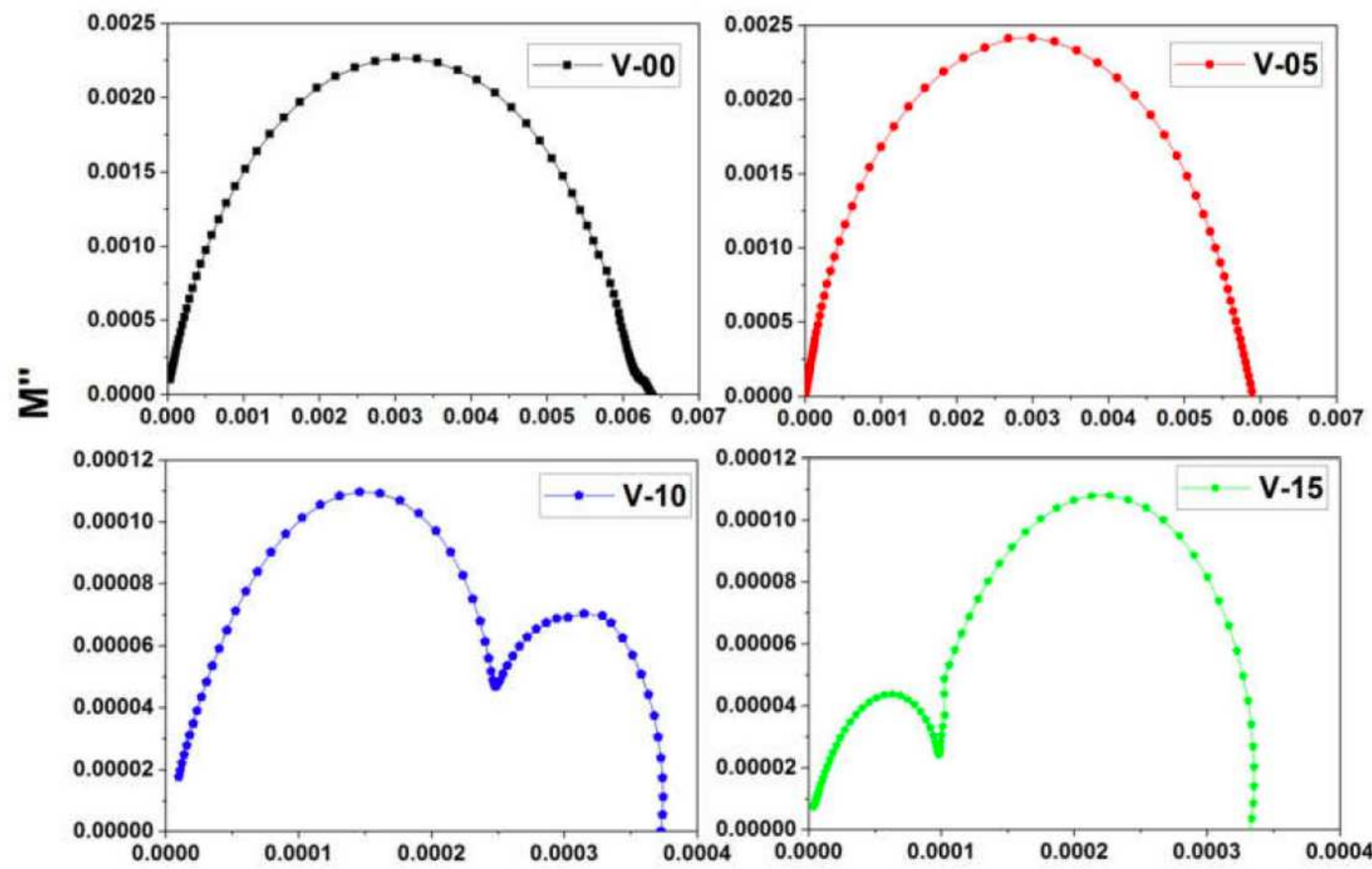

$M^{\prime}$

Figure 8

Cole-Cole plots of all the samples. 